\title{
Modelling of Passive Heat Removal Systems: A Review with Reference to the Framatome KERENA BWR Reactor: Part I
}

\author{
Amirhosein Moonesi Shabestary ${ }^{1,2, *} \mathbb{0}$, Frances Viereckl ${ }^{3}$, Yu Zhang ${ }^{4,5}$, Rene Manthey ${ }^{3}$, \\ Dirk Lucas ${ }^{1}$, Christoph Schuster ${ }^{3}$, Stephan Leyer ${ }^{4}$, Antonio Hurtado ${ }^{3}$ and Uwe Hampel ${ }^{1,2}$ \\ 1 Institute of Fluid Dynamics, Helmholtz-Zentrum Dresden-Rossendorf (HZDR), 010328 Dresden, Germany; \\ d.lucas@hzdr.de (D.L.); u.hampel@hzdr.de (U.H.) \\ 2 Chair of Imaging Techniques in Energy and Process Engineering, Technische Universität Dresden, \\ 01062 Dresden, Germany \\ 3 Chair of Hydrogen and Nuclear Energy, Technische Universität Dresden, 01062 Dresden, Germany; \\ frances.viereckl@tu-dresden.de (F.V.); rene.manthey@tu-dresden.de (R.M.); \\ christoph.schuster@tu-dresden.de (C.S.); antonio.hurtado@tu-dresden.de (A.H.) \\ 4 Faculty of Civil and Construction Engineering, Technische Hoschschule Deggendorf, 94469 Deggendorf, \\ Germany; yu.zhang@th-deg.de (Y.Z.); stephan.leyer@uni.lu (S.L.) \\ 5 Faculty of Science, Technology and Communication, University of Luxembourg, \\ 4365 Luxembourg, Luxembourg \\ * Correspondence: a.moonesi@hzdr.de
}

Received: 23 November 2019; Accepted: 17 December 2019; Published: 19 December 2019

check for updates

\begin{abstract}
Passive safety systems are an important feature of currently designed and constructed nuclear power plants. They operate independent of external power supply and manual interventions and are solely driven by thermal gradients and gravitational force. This brings up new needs for performance and reliably assessment. This paper provides a review on fundamental approaches to model and analyze the performance of passive heat removal systems exemplified for the passive heat removal chain of the KERENA boiling water reactor concept developed by Framatome. We discuss modelling concepts for one-dimensional system codes such as ATHLET, RELAP and TRACE and furthermore for computational fluid dynamics codes. Part I deals with numerical and experimental methods for modelling of condensation inside the emergency condensers and on the containment cooling condenser while part II deals with boiling and two-phase flow instabilities.
\end{abstract}

Keywords: passive heat removal systems; condensation; 1D codes; CFD; emergency condensers; containment cooling condensers

\section{Introduction}

Nuclear safety plays a central role in the design and operation of nuclear power plants. Hence, industry and regulatory bodies have in the past continuously improved safety features and safety regulations in this field [1]. Amongst others, this becomes apparent in the classification of nuclear reactors into four generations, basing on safety, cost effectiveness, grid appropriateness (Figure 1) [2]. GEN I reactors were mainly developed and constructed between 1950-1970 as prototypes and power reactors for the public electricity supply. With further development of safety and economical features, GEN II nuclear reactors were introduced. Such are e.g., Boiling Water Reactors (BWR), Pressurized Water Reactors (PWR), CANada Deuterium Uranium reactors (CANDU) and Vodo-Vodyanoi Energetichesky Reactors (VVER). GEN II reactors, which are mainly Light Water Reactors (LWR), are essentially equipped with active safety functions which need electrical and mechanical supplies. Accidents in 
Three Miles Island in 1979, Chernobyl in 1986 and Fukushima Daiichi in 2011 raised questions of the adequacy of having only active safety components, which led to the development of GEN III/GEN III+ reactors. These are fundamentally GEN II designs with improvements in thermal efficiency and safety systems and with passive safety systems [2].

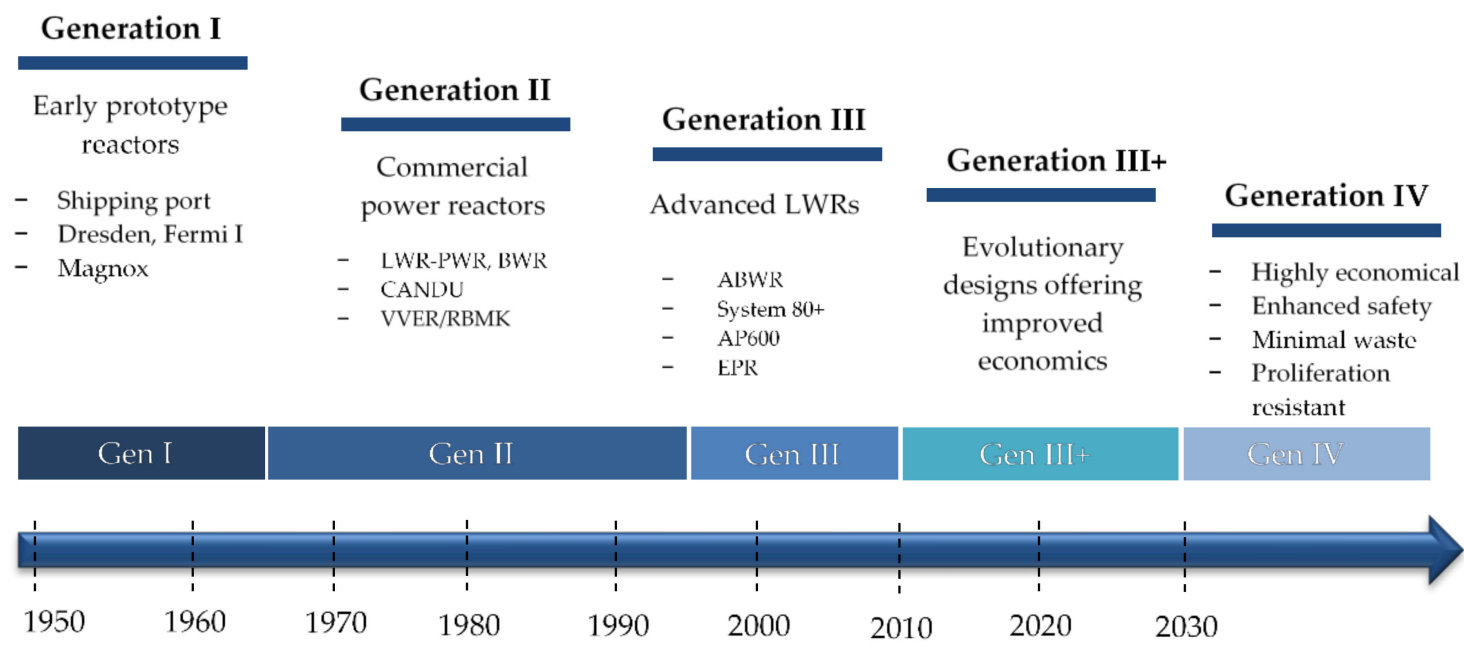

Figure 1. Evolution of nuclear power plants by time [2].

The activation and operation of passive safety systems are independent of active components like pumps or emergency electrical supplies as well as manual intervention. Instead, they rely on gravity, natural convection, as well as condensation and boiling [2,3]. Further to the improvements in safety aspects, passive systems have an impact on manufacturing cost reduction as they have fewer expensive active components, such as pumps [3]. Substitution by or combination of active safety systems with passive systems is supposed to reduce core damage probability by three orders of magnitude in comparison to GEN II nuclear power plants [4,5]. Therefore, the AP1000, for instance, is specified with a core damage frequency of about $2.4 \times 10^{-7}$ per year and with an attainable waiting period of $72 \mathrm{~h}$ [6].

Passive safety systems can be categorized by the driving forces and the initialization of their activation. The International Atomic Energy Agency (IAEA) provides classified definitions in different categories of passivity with respect to driving and initial forces as well as moving mechanical parts [3]. Passive systems in GEN III/GEN III+ reactors have two main functions: decay heat removal from the reactor core after scram and heat removal and depressurization of the containment. The first one type is classified as:

- $\quad$ Pre-pressurized core flooding tanks

- Elevated tank natural circulation loops

- Elevated gravity drain tanks

- Passively cooled steam generators or natural circulation

- Passive residual heat removal heat exchangers

- Passively cooled core isolation condensers

- Sump natural circulation

For heat removal and depressurization of the containment advanced reactors dispose of e.g.,:

- Containment pressure suppression pools

- Containment passive heat removal/pressure suppression systems

- Passive containment spraying

An overview on the implemented passive safety systems in the available GEN III/GEN III+ nuclear reactor designs is given in Table 1. 
Table 1. Summary of passive safety systems and their application in advanced reactor designs [3].

\begin{tabular}{|c|c|c|c|c|}
\hline Function & $\begin{array}{c}\text { Passive Safety } \\
\text { System }\end{array}$ & Reactor Design & Reactor Type & Power (MW.th \\
\hline \multirow{28}{*}{$\begin{array}{l}\text { Core decay heat } \\
\text { removal }\end{array}$} & \multirow{6}{*}{$\begin{array}{l}\text { Pre-pressurized core } \\
\text { flooding tanks }\end{array}$} & AP1000 & PWR & 3415 \\
\hline & & WWER-640/V-407, WWER-1000/V-392 & PWR & 1800,3000 \\
\hline & & APWR+ & PWR & 5000 \\
\hline & & ESBWR & BWR & 4500 \\
\hline & & AHWR & HWR & 750 \\
\hline & & SMART & PWR & 330 \\
\hline & \multirow{4}{*}{$\begin{array}{l}\text { Elevated tank natural } \\
\text { circulation loops }\end{array}$} & AP1000 & PWR & 3415 \\
\hline & & WWER-1000/V-392 & PWR & 3000 \\
\hline & & ACR1000 & HWR & 3180 \\
\hline & & SCWR-CANDU & SCWR & 2540 \\
\hline & \multirow{9}{*}{$\begin{array}{c}\text { Elevated gravity drain } \\
\text { tanks }\end{array}$} & SWR1000 & BWR & 2778 \\
\hline & & AP1000 & PWR & 3415 \\
\hline & & WWER-640/V-407 & PWR & 1800 \\
\hline & & SBWR, ESBWR & BWR & 2000,4500 \\
\hline & & LSBWR & BWR & 900 \\
\hline & & AHWR & HWR & 750 \\
\hline & & ACR1000 & HWR & 3180 \\
\hline & & SCWR-CANDU & SCWR & 2540 \\
\hline & & IRIS & PWR & 1000 \\
\hline & \multirow{6}{*}{$\begin{array}{l}\text { Passively cooled steam } \\
\text { generator or natural } \\
\text { circulation }\end{array}$} & WWER-640/V-407, WWER-1000/V-392 & PWR & 1800,3000 \\
\hline & & SMART & PWR & 330 \\
\hline & & PSRD & PWR & 100 \\
\hline & & IMR & PWR & 1000 \\
\hline & & IRIS & PWR & 1000 \\
\hline & & APWR+ & PWR & 5000 \\
\hline & \multirow{3}{*}{$\begin{array}{l}\text { Passive residual heat } \\
\text { removal heat } \\
\text { exchanger }\end{array}$} & AP1000 & PWR & 3415 \\
\hline & & SCWR-CANDU & SCWR & 2540 \\
\hline & & SCOR & PWR & 2000 \\
\hline
\end{tabular}


Table 1. Cont.

\begin{tabular}{|c|c|c|c|c|}
\hline Function & $\begin{array}{c}\text { Passive Safety } \\
\text { System }\end{array}$ & Reactor Design & Reactor Type & Power (MW.th) \\
\hline & \multirow{6}{*}{$\begin{array}{l}\text { Passive cooled core } \\
\text { isolation condensers }\end{array}$} & SWR1000 & BWR & 2778 \\
\hline & & SBWR and ESBWR & BWR & 2000,4500 \\
\hline & & ABWR-II & BWR & 4960 \\
\hline & & RMWR & BWR & 3926 \\
\hline & & AHWR & HWR & 750 \\
\hline & & CAREM & PWR & 100 \\
\hline & \multirow{3}{*}{$\begin{array}{l}\text { Sump natural } \\
\text { circulation }\end{array}$} & AP1000 & PWR & 3415 \\
\hline & & WWER-640/V-407 & PWR & 1800 \\
\hline & & MASLWR & PWR & 150 \\
\hline \multirow{17}{*}{$\begin{array}{l}\text { Containment } \\
\text { cooling or pressure } \\
\text { suppression }\end{array}$} & \multirow{6}{*}{$\begin{array}{l}\text { Containment pressure } \\
\text { suppression pools }\end{array}$} & AP1000 & PWR & 3415 \\
\hline & & SBWR and ESBWR & BWR & 2000,4500 \\
\hline & & LSBWR & BWR & 900 \\
\hline & & CAREM & PWR & 100 \\
\hline & & SCOR & PWR & 2000 \\
\hline & & IRIS & PWR & 1000 \\
\hline & \multirow{7}{*}{$\begin{array}{l}\text { Containment passive } \\
\text { heat removal/pressure } \\
\text { suppression systems }\end{array}$} & SWR1000 & BWR & 2778 \\
\hline & & AHWR & HWR & 750 \\
\hline & & WWER-640/V-407 & PWR & 1800 \\
\hline & & PSRD & PWR & 100 \\
\hline & & SBWR and ESBWR & BWR & 2000,4500 \\
\hline & & ABWR-II & BWR & 4960 \\
\hline & & RMWR & BWR & 3926 \\
\hline & \multirow{4}{*}{$\begin{array}{l}\text { Passive containment } \\
\text { spray systems }\end{array}$} & AP1000 & PWR & 3415 \\
\hline & & LSBWR & BWR & 900 \\
\hline & & ACR1000 & HWR & 3180 \\
\hline & & SCWR-CANDU & SCWR & 2540 \\
\hline
\end{tabular}




\section{KERENA (SWR 1000) Reactor}

The KERENA (SWR 1000) nuclear reactor is a GEN III+ boiling water reactor developed by Framatome. KERENA is specified for $1250 \mathrm{MWe}$ electrical power and a life-time of 60 years. It comprises of a number of innovative passive safety systems. The KERENA concept and the safety features are depicted in Figure 2. In case of a failure of active systems four emergency condensers (EC) (Figure 1-Pos. 2) remove the decay heat from the reactor pressure vessel (RPV). They are hydraulically connected to the RPV and become passively activated when the water level in the reactor increases to their geodetic height. When activated they condense steam and thus transfer the decay heat into the flooding pool, which acts as an intermediate heat sink. This system substitutes the high-pressure injection in the high-pressure path of older designs [7]. In addition, the water in the flooding pool serves as coolant for replenishing the RPV within the low-pressure path (Figure 1-Pos. 3). Another passive safety component is the passive pulse pressure transmitter (PPPT) (Figure 1-Pos. 5/7/8). The PPPT is a heat exchanger that acts as a diversity system for the activation of scram, the main steam line isolation valves and the safety relief valve, which can now be activated without any electrical supply. When the water level inside the RPV decreases, steam will flow through the shell side of the PPPT and will condense on the cold tube surface. The heat flux evaporates the fluid inside the tubes, which leads to an increasing pressure on the secondary side and this way activates safety related functions by control valves. Experimental investigations on this component were published in [8,9]. The main parts of the safety system of the KERENA reactor are summarized in Table 2.

Next in the passive heat transfer chain are the four containment cooling condensers (CCC), which consist of slightly inclined horizontal tubes (Figure 1-Pos. 1). Their task is to transfer heat from the containment into the storage and shielding pool. Possible causes for a containment temperature rise are either opening of the safety relief valve and steam release from the reactor circuit into the containment (Figure 1-Pos. 5.2/5.3) or the continuous heat-up of the flooding pool via the emergency condensers. The pipes of the CCC are connected to the shielding/storage pool, which is a source of subcooled water. The heat transfer drives a natural circulation flow that transports the heat from the containment to the storage pool. The flow direction within the condensation tubes is determined by the slight inclination.

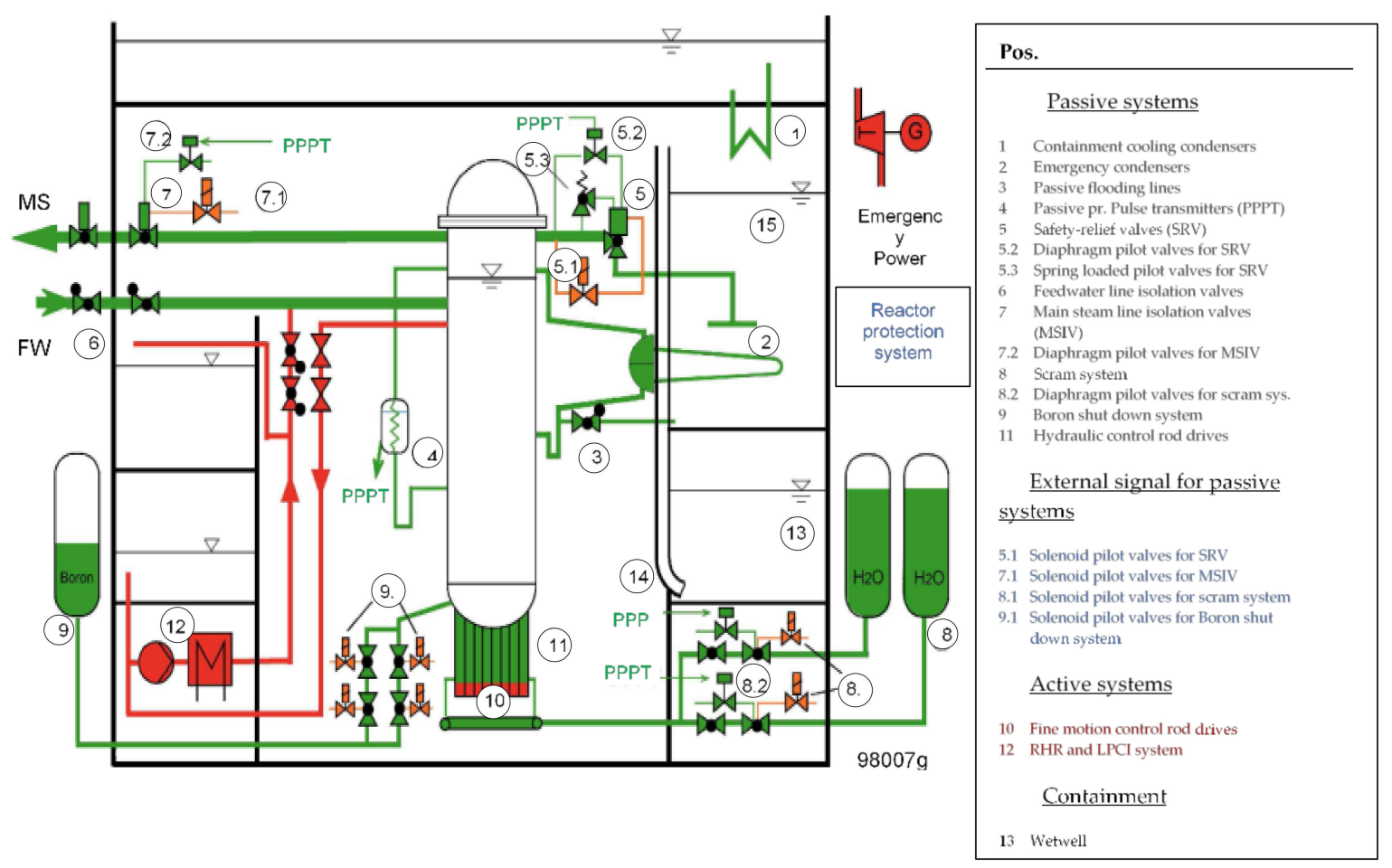

Figure 2. The KERENA reactor and its safety feature [5]. 
Table 2. Passive and active safety systems of the KERENA (formerly SWR1000) [3,9].

\begin{tabular}{|c|c|c|c|c|}
\hline Safety Functions & \multicolumn{3}{|c|}{ Passive Safety Systems } & Active Safety Systems \\
\hline $\begin{array}{l}\text { Decay heat removal from } \\
\text { containment }\end{array}$ & \multicolumn{3}{|c|}{ Four containment cooling condensers } & Two residual decay heat \\
\hline Core flooding (low pressure) & \multicolumn{3}{|c|}{ Four core flooding lines } & flooding systems \\
\hline $\begin{array}{l}\text { Decay heat removal from } \\
\text { RPV (low pressure) }\end{array}$ & \multirow{2}{*}{\multicolumn{3}{|c|}{ Four emergency condensers }} & \\
\hline $\begin{array}{l}\text { Decay heat removal from } \\
\text { RPV (high pressure) }\end{array}$ & & & & \\
\hline $\begin{array}{l}\text { Limitation of reactor } \\
\text { pressure }\end{array}$ & \multirow{2}{*}{$\begin{array}{l}\text { Six safety } \\
\text { relief valves }\end{array}$} & $\begin{array}{l}\text { Solenoid valve, } \\
\text { Spring loaded } \\
\text { control valve }\end{array}$ & & \\
\hline Relief of reactor pressure & & $\begin{array}{l}\text { Diaphragm valve, } \\
\text { Solenoid valve }\end{array}$ & $\begin{array}{l}\text { Emergency } \\
\text { condenser }\end{array}$ & \\
\hline $\begin{array}{l}\text { Penetration isolation of main } \\
\text { steam-line }\end{array}$ & \multicolumn{3}{|c|}{$\begin{array}{l}\text { Two intrinsic medium actuated quick-closing } \\
\text { valves per line: } \\
\text {-diaphragm valve/PPPT (passive C) } \\
\text {-solenoid valve (passive D) }\end{array}$} & Gate valve \\
\hline Subcriticality & \multicolumn{3}{|c|}{$\begin{array}{l}\text { Scram-system (four accumulators) } \\
\text {-diaphragm valve/PPPT (passive C) } \\
\text {-solenoid valve (passive D) }\end{array}$} & $\begin{array}{l}137 \text { electrical devices } \\
\text { Boron shut-down system }\end{array}$ \\
\hline
\end{tabular}

In order to investigate the behaviour and performance of the passive safety systems in different accident scenarios, several test facilities were constructed worldwide. For the KERENA and AP1000 reactors the integral test facilities INKA [10] and APEX-1000 [11] have been set up. Next to integral test facilities, which are dedicated to study accident scenarios on the system scale, many dedicated small-scale test facilities, such as NOKO/TOPFLOW [7], PANDA [12], PUMA [13], SIRIUS [14], CIRCUS [15], DANTON [9,16] and GENEVA [17] do exists, they have been or are being used for single effect and component studies for passive heat removal systems. Juhn et al. [18] provided a detailed overview of the research projects with respect to technical enhancement of safety systems.

For predicting the operational performance of thermal hydraulic circuits on the plant scale under various accident scenarios several one-dimensional codes such as ATHLET, RELAP and TRACE are widely used in nuclear community. However, these codes have been mainly qualified so far for active hydraulic systems. Qualifying them for passive systems is still a challenging task. For instance, for modelling the condensation process inside emergency condensers, there is a necessity to derive suitable heat transfer models, do experimental validation [7,19] and code-to-code comparisons [20].

In this paper, we present a review on the current state of knowledge about phenomena governing passive heat removal with reference to the KERENA concept. The considered phenomena are: condensation inside and on the inclined tubes, boiling inside and on the inclined tubes and stability of the natural circulation. Thereby, we review numerical studies and developed heat transfer correlations for steam condensation used in one-dimensional system codes and in computational fluid dynamics codes (CFD). Moreover, the experimental facilities, which have been used for single effect investigations in this field during the last years, are introduced. In part II, a review of research activities on boiling and stability is presented.

\section{Condensation Inside Inclined Tubes}

The first stage in the heat transfer chain of the KERENA reactor is the emergency condenser (EC). It becomes operative when the water level in reactor pressure vessel drops. The primary circuit is depressurized and cooled via steam condensation in four horizontal tube bundles. Modelling of this component requires a profound understanding of high-pressure steam condensation inside inclined tubes. 


\subsection{Flow Characteristics}

The condensation process inside inclined tubes is illustrated in Figure 3. Saturated or superheated steam enters the pipe at the inlet. The steam is condensed on the cold wall at condensation sites, which provide the necessary microscopic energy conditions. The steam condenses first into droplets when the wall has a low wettability. The droplets grow and get mobilized due to interfacial shear and gravity. Depending on the wettability and local flow conditions, droplets merge and generate a thin liquid film that results in annular flow.

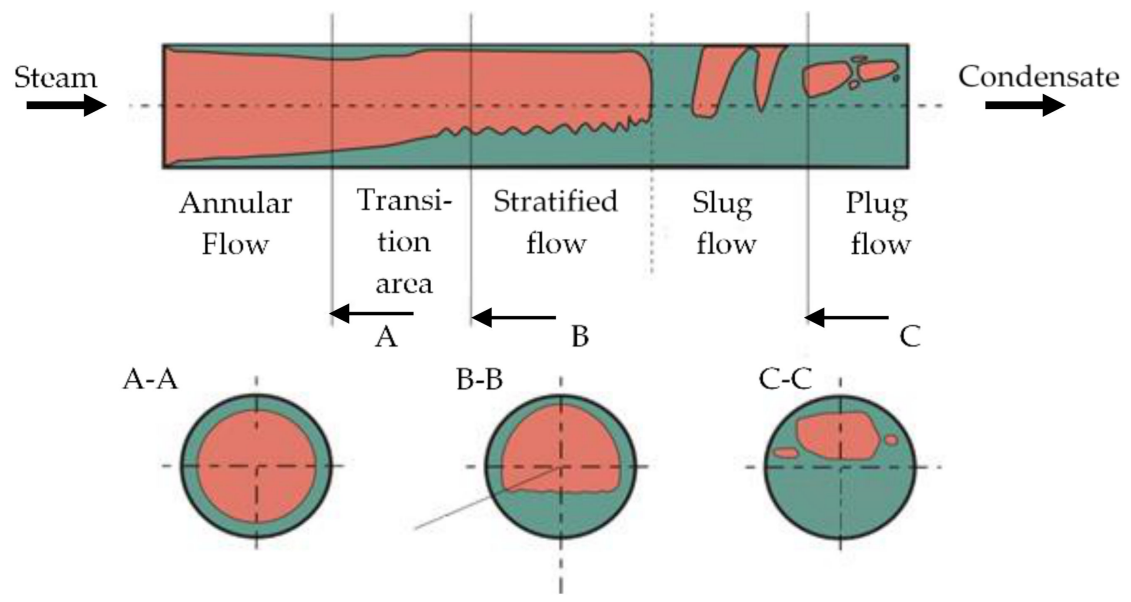

Figure 3. Two-phase flow patterns of the condensation process in a horizontal tube [7].

With further progressing condensation on the gas-liquid interface the liquid film growths and changes into a turbulent and wavy annular flow. Due to action of gravity, the film is radially asymmetric in horizontal and inclined pipes. Accumulation of a liquid flume on the lower part of the tube results in generation of a stratified flow. After some distance the void fraction becomes small enough such that the flow regime changes. By growth of the waves at the steam-liquid interface, liquid slugs and large bubbles appear. For tubes with smaller diameter a developed slug flow forms, however, for larger tubes the liquid-steam interface stays agitated which is called churn-turbulent flow [21].

Since different flow regimes result in different heat transfer coefficients and condensation rates, prediction of the two-phase flow morphology is a critical point. The two-phase flow inside tubes is commonly described by flow pattern maps. The first general flow pattern map for horizontal two-phase gas-liquid flow goes back to the Baker map (1954) [22], which combines the superficial gas with liquid velocities. Following the Baker map many other flow maps were developed (White and Huntington, 1955 [23]; Govier and Omer, 1962 [24]).

Traviss and Rohsenow [25] studied in-tube condensation with R-12 in an $8 \mathrm{~mm}$ tube and found that the flow well matched with the Baker map. However, some controversy has been raised concerning the application of the Baker map for condensation. Initially, Soliman and Azer [26] found a non-conformity to the Baker map for the wavy regime of R-12 in a $12.7 \mathrm{~mm}$ tube during condensation. The same authors [27] later studied R-113 condensation in $4.75 \mathrm{~mm}, 12.7 \mathrm{~mm}$ and $16.15 \mathrm{~mm}$ tubes and found the same inconsistency. Taitel, and Dukler [28] developed a flow pattern map, which is based on mechanistic considerations. They defined five dimensionless groups corresponding to the fluid dynamic parameters, the tube geometry and the tube inclination angle. The flow map includes annular, stratified wavy, stratified smooth, intermittent and bubbly flow. This map is one of the most reliable and frequently used flow maps and has been used as a basis to develop new flow pattern maps. Breber et al. [29] stated that the Taitel and Dukler map is in good agreement with the condensation flow pattern data for tube diameters ranging from $8 \mathrm{~mm}$ to $22 \mathrm{~mm}$, while for a tube diameter of $4.8 \mathrm{~mm}$ (Soliman's [30] database) there is a large discrepancy due to negligence of surface tension effects. Later, El Hajal et al. [31] developed a new flow pattern map according to the Kattan-Thome-Favrat [32] map 
based on a logarithmic mean void fraction in order to span the entire range from low pressure up to the critical point.

Tandon et al. [33] suggested a flow regime map with dimensionless gas velocity $j_{g}=\frac{x \dot{m}}{\sqrt{g D \rho_{g}\left(\rho_{1}-\rho_{g}\right)}}$ as ordinate and void fraction ratio $(1-\alpha) / \alpha$ as abscissa based on Soliman et al. [26]. The map was validated for 662 experimental data points of R-12 and R-113 condensation in horizontal tubes with diameters from $4.8 \mathrm{~mm}$ to $15.9 \mathrm{~mm}$ (see Figure 4). Recently, Zhuang et al. [34] proposed a flow pattern map for R170 that considers effects of vapor inertia and liquid viscous as well as surface tension forces on the transition regime.

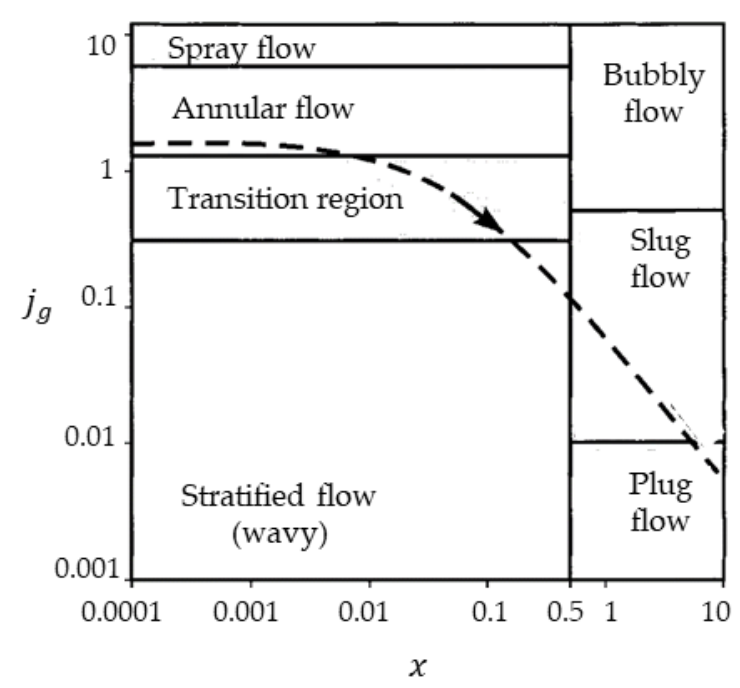

Figure 4. Tandon et al. flow pattern map [33].

\subsection{Heat Transfer Correlations}

As heat transfer in two-phase flow conditions is strongly coupled to flow regime there are a number of different heat transfer correlations. The most relevant ones are summarized in Table 3 and will be briefly introduced in this section.

In 1962, Chato [35] investigated the influence of oil on condensation heat transfer for the refrigerant R113. He reported a reduction in heat transfer coefficient due to the presence of oil and assumed that condensation is different in two regions, Figure 5. In the upper pipe section, the heat transfer is through the thin condensed oil film. He considered that the temperature variation of the wall along the cross section has an insignificant effect. Therefore, he argued that the heat transport in the lower area of the pipe is negligible. Based on this principle, he developed a correlation that is an extension of the Nusselt theory [36]. It is only applicable if the shear stress of steam is low, that is, for Reynolds numbers lower than 35,000 .

Boyko et al. [37] predicted the heat transfer of the steam condensation inside a tube on the basis of an analogy between heat transfer and hydraulic resistance in dependence on the Reynolds number. Experiments were conducted with a tube of $18 \mathrm{~mm}$ diameter of $12 \mathrm{~m}$ lengths at pressures up to $90 \mathrm{bar}$. The theoretical and the experimental results were in good agreement.

Kosky et al. [38] experimentally investigated annular condensation inside a tube and derived correlations for calculation of thermal resistance of the falling film based on a modification of the Martinelli analogy, which considers the dimensionless temperature and velocity between heat and momentum transfer in turbulent flow. 


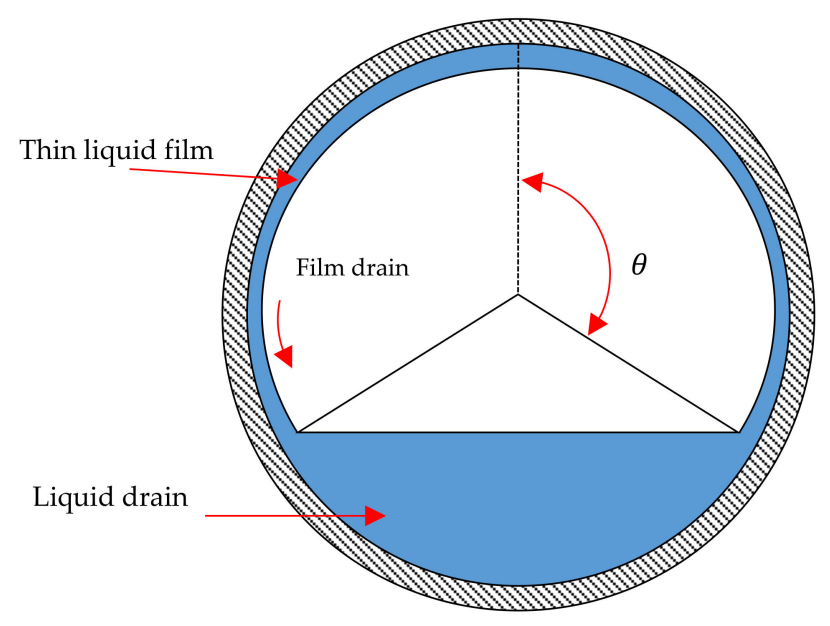

Figure 5. Stratified condensation of the mixture of oil-refrigerant [35].

Chen et al. [39] proposed a film condensation model which considers the effects of interfacial shear stress, interfacial waviness and turbulence transport in the liquid film. The correlation was validated for different scenarios such as a vertical surface in both stationary and moving conditions as well as vertical and horizontal concurrent pipe flows.

Dobson and Chato [40] performed an experiment with refrigerants in horizontal smooth tubes with diameters ranging from $3.14 \mathrm{~mm}$ to $7.04 \mathrm{~mm}$. On the basis of conducted experiments, a new flow regime map and an improved version of Chato correlation were introduced.

Moser et al. [41] developed an equivalent heat transfer model that is based on the heat-momentum diffusive transport equation. The model was applied to predict the experimental Nusselt number of 1197 data points from 18 sources with an average deviation of 13.64 percent for tube internal diameters between $3.14 \mathrm{~mm}$ and $20 \mathrm{~mm}$.

Sarma et al. [42] used a homogeneous approach to estimate friction velocity and derived a correlation for heat transfer coefficient. They considered the frictional pressure drop by introducing a friction multiplier. They got an average deviation of $+5 \%$, an absolute mean deviation of $12 \%$ and a standard deviation of $19 \%$ for a total number of 5478 data points.

Cavallini et al. [43] developed a predictive method based on flow patterns occurring during condensation. The model was validated with a wide range of refrigerants R-22, R-134a, R-125, R-32 and R-410A for an $8 \mathrm{~mm}$ diameter plain tube. Later on, Cavallini [44] found that condensation heat transfer is not always dependent on temperature difference but other parameters like mass velocity, saturation temperature, vapor quality and geometry. He introduced a more simplified and general model for tubes with an internal diameter larger than $3 \mathrm{~mm}$. The correlation has lower uncertainty compared to the previous one.

Shah [45] proposed a simple dimensionless correlation which was validated on a wide set of experimental data from highly turbulent flow to laminar flow conditions. The validation database includes 22 different fluids including horizontal, vertical, and downward-inclined tubes. The range of parameters is from $2 \mathrm{~mm}$ to $49 \mathrm{~mm}$ tube diameter, flow rates from $4 \frac{\mathrm{kg}}{\mathrm{m}^{2} \mathrm{~s}}$ to $820 \frac{\mathrm{kg}}{\mathrm{m}^{2} \mathrm{~s}}$, and liquid Reynolds numbers from 68 to 85,000 .

The above correlations have been derived from various experimental data, often not for water/steam. In order to assess their validity for nuclear applications, that is, high pressure steam condensation, we tested them against experimental data obtained at the COSMEA facility (Section 4) [46]. Exemplarily, we show results for three experiments at 45 bar pressure (Figure 6). More detailed information about boundary conditions and geometry of experiments can be found in [46]. The comparison shows, that the Dobson model is in very good agreement with the experimental data, while the other models do significantly underestimate the condensation rate. 


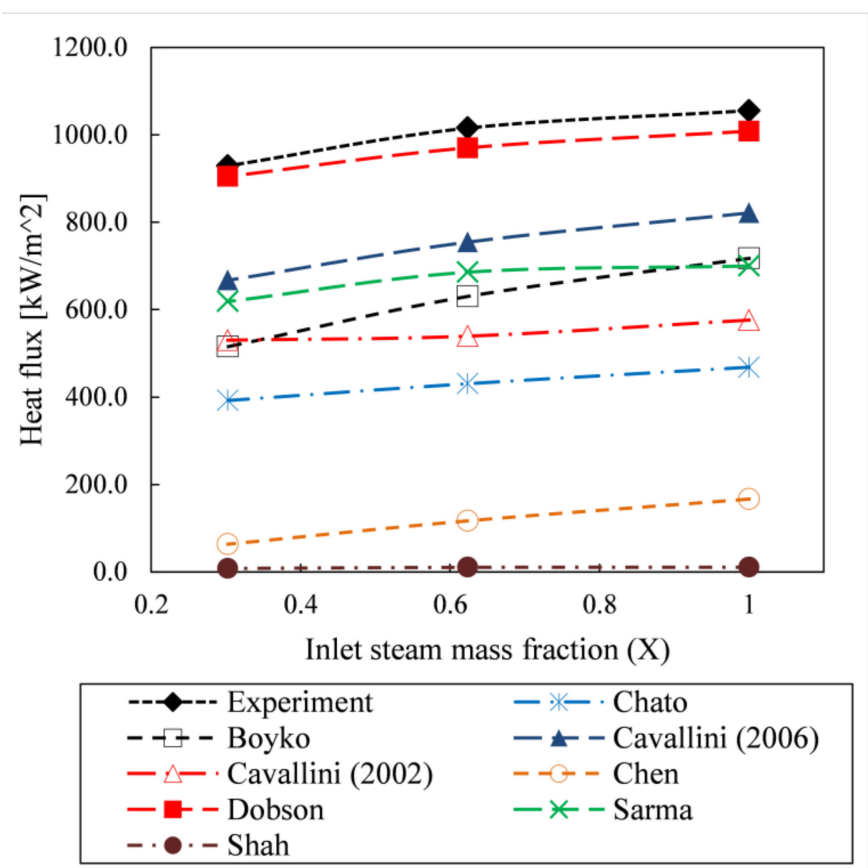

Figure 6. Heat flux versus inlet steam mass fraction, a comparison between experiment (COSMEA) and calculated results with different heat transfer correlations.

Table 3. Heat transfer correlations for in-tube condensation.

\begin{tabular}{|c|c|}
\hline Authors (Year) Reference & Correlations \\
\hline Chato (1962) [35] & $\begin{array}{l}\mathrm{h}=0.728 \varepsilon^{*}\left[\frac{\rho_{1}\left(\rho_{1}-\rho_{\mathrm{v}}\right) g \Delta \mathrm{i}_{\mathrm{iv}} \lambda_{1}^{3}}{\mu_{1} \mathrm{D}\left(\mathrm{T}_{\mathrm{sat}}-\mathrm{T}_{\mathrm{w}}\right)}\right]^{0.25} \\
\varepsilon^{*}=\mathrm{x} /\left(\mathrm{x}+(1-\mathrm{x})\left(\frac{\rho_{\mathrm{v}}}{\rho_{1}}\right)^{\frac{2}{3}}\right)\end{array}$ \\
\hline Boyko, L.D. (1967) [37] & $\mathrm{h}=0.024 \frac{\lambda_{1}}{\mathrm{D}} \operatorname{Re}_{1}^{0.8} \operatorname{Pr}_{1}^{0.43} \frac{\sqrt{\left(1+\frac{\rho_{1}-\rho_{\mathrm{v}}}{\rho_{\mathrm{v}}} \mathrm{x}\right)}}{2}$ \\
\hline Chen (1987) [39] & $\mathrm{h}=0.018\left(\frac{\rho_{1}}{\rho_{\mathrm{v}}}\right)^{0.39}\left(\frac{\mu_{\mathrm{l}}}{\mu_{\mathrm{v}}}\right)^{0.078} \operatorname{Re}_{1}^{0.2}\left(\operatorname{Re}_{\mathrm{T}}-\operatorname{Re}_{1}\right)^{0.7} \operatorname{Pr}_{1}^{0.65}$ \\
\hline Dobson and Chato (1998) [40] & $\begin{array}{l}\mathrm{h}=\frac{\lambda_{1}}{\mathrm{D}}\left[\frac{0.23 \mathrm{Re}_{v}^{0.12}}{1+1.11 X_{\mathrm{tt}}^{0.58}}\left(\frac{\mathrm{Ga}_{1} \operatorname{Pr}_{1}}{\mathrm{Ja}_{1}}\right)^{0.25}+\left(1-\frac{\theta}{\pi}\right) 0.0195 \operatorname{Re}_{1}^{0.8} \operatorname{Pr}_{1}^{0.4} \varphi\left(\mathrm{X}_{\mathrm{tt}}\right)\right. \\
\varphi\left(\mathrm{X}_{\mathrm{tt}}\right)=\sqrt{1.376+\frac{\mathrm{C}_{1}}{\mathrm{X}_{\mathrm{tt}}}}, \mathrm{X}_{\mathrm{tt}}=\left(\frac{1-\mathrm{x}}{\mathrm{X}}\right)^{0.9}\left(\frac{\rho_{\mathrm{v}}}{\rho_{1}}\right)^{0.5}\left(\frac{\mu_{1}}{\mu_{\mathrm{v}}}\right)^{0.1} \\
\mathrm{Ga}_{1}=\frac{\mathrm{g}_{1}\left(\rho_{1}-\rho_{\mathrm{v}}\right) \mathrm{D}^{3}}{\mu_{1}}, \mathrm{Ja}_{1}=\frac{\mathrm{c}_{\mathrm{p}, 1}\left(\mathrm{~T}_{\mathrm{s}}-\mathrm{T}_{\mathrm{w}}\right)}{\mathrm{H}_{\text {evap }}} \\
\text { For } 0<\mathrm{Fr}_{1} \leq 0.7 \\
\mathrm{C}_{1}=4.172+5.48 \mathrm{Fr}_{1}-1.564 \mathrm{Fr}_{1}^{2} \\
\mathrm{C}_{2}=1.773-0.169 \mathrm{Fr}_{1} \\
\text { For } 0.7<\mathrm{Fr}_{1} \\
\mathrm{C}_{1}=7.242 \\
\mathrm{C}_{2}=1.655\end{array}$ \\
\hline Sarma (2002) [42] & $\mathrm{h}=0.023 \frac{\lambda_{\mathrm{f}}}{\mathrm{D}} \operatorname{Re}_{1}^{0.8} \operatorname{Pr}_{1}^{0.4}(1-\mathrm{x})^{0.8}\left[1+2.164\left(\frac{\mathrm{x}}{1-\mathrm{x}}\right)^{0.85}\left(\frac{\mathrm{P}_{\text {Crit }}}{\mathrm{P}}\right)^{0.565}\right]$ \\
\hline Cavallini (2002) [43] & $\begin{array}{l}\mathrm{h}= \\
0.725\left[\frac{\rho_{1}\left(\rho_{1}-\rho_{\mathrm{v}}\right) \mathrm{gh}_{\mathrm{lv}} \lambda_{1}^{3}}{\mu_{1} \mathrm{D}\left(\mathrm{T}_{\mathrm{s}}-\mathrm{T}_{\mathrm{w}}\right)}\right]^{\frac{1}{4}}\left[1+0.82\left(\frac{1-\mathrm{x}}{\mathrm{x}}\right)^{0.268}\right]^{-1}+\mathrm{h}_{\mathrm{LO}}(1-\mathrm{x})^{0.8}\left(1-\frac{\theta_{\text {strat }}}{\pi}\right) \\
\mathrm{h}_{\mathrm{LO}}=0.023 \operatorname{Re}_{\mathrm{LO}}^{0.8} \operatorname{Pr}_{1}^{0.4}\left(\frac{\mathrm{k}_{1}}{\mathrm{D}}\right)\end{array}$ \\
\hline
\end{tabular}


Table 3. Cont

\begin{tabular}{|c|c|}
\hline Authors (Year) Reference & Correlations \\
\hline Cavallini (2006) [44] & $\begin{array}{l}\mathrm{J}_{\mathrm{v}}=\frac{\varepsilon \cdot \mathrm{G}}{\left[\mathrm{g} \cdot \mathrm{D} \cdot \rho_{\mathrm{v}} \cdot\left(\rho_{1}-\rho_{\mathrm{v}}\right)\right]^{0.5}} \\
\mathrm{~J}_{\mathrm{V}}^{\mathrm{T}}=\left\{\left[\frac{7.5}{4.3 X_{\mathrm{tt}}^{1.111}+1}\right]^{-3}+\mathrm{C}_{\mathrm{T}}^{-3}\right\}^{-1 / 3} \\
\text { For hydrocarbons, } \mathrm{C}_{\mathrm{T}}=1.6 \text {; other refrigerants, } \mathrm{C}_{\mathrm{T}}=2.6 \\
\text { a) for } \mathrm{J}_{\mathrm{v}}^{\mathrm{T}}<\mathrm{J}_{\mathrm{V}}, \Delta \mathrm{T} \text { independent flow regime } \\
\mathrm{h}_{\mathrm{I}}=\mathrm{h}_{\mathrm{L} 0}\left[1+1.128 \varepsilon^{0.8170}\left(\frac{\rho_{1}}{\rho_{\mathrm{v}}}\right)^{0.3685}\left(\frac{\mu_{1}}{\mu_{\mathrm{v}}}\right)^{0.2363}\left(1-\frac{\mu_{\mathrm{v}}}{\mu_{1}}\right)^{2.144} \operatorname{Pr}_{1}^{-0.1}\right] \\
\text { b) for } \mathrm{J}_{\mathrm{v}}^{\mathrm{T}}>\mathrm{J}_{\mathrm{v}}, \Delta \mathrm{T} \text { dependent flow regime } \\
\mathrm{h}=\left[\mathrm{h}_{\mathrm{I}}\left(\frac{\mathrm{J}_{\mathrm{v}}^{\mathrm{T}}}{\mathrm{J}_{\mathrm{v}}}\right)^{0.8}-\mathrm{h}_{\mathrm{STRAT}}\right]\left(\frac{\mathrm{J}_{\mathrm{v}}}{\mathrm{J}_{\mathrm{v}}^{\mathrm{T}}}\right)+\mathrm{h}_{\mathrm{STRAT}} \\
\mathrm{h}_{\mathrm{L} 0}=0.023 \operatorname{Re}_{1}^{0.8} \operatorname{Pr}_{1}^{0.4} \frac{\lambda_{1}}{\mathrm{D}} \\
\mathrm{h}_{\mathrm{STRAT}}= \\
0.725\left\{1+0.741\left[\left(\frac{1-\varepsilon}{\varepsilon}\right)^{0.3321}\right]\right\}^{-1}\left[\frac{\lambda_{1}^{3} \rho_{1}\left(\rho_{1}-\rho_{\mathrm{v}}\right) g \Delta \mathrm{i}_{\mathrm{lv}}}{(\mu \mathrm{D} \Delta \mathrm{T})}\right]^{0.25}+\left(1-\varepsilon^{0.087}\right) \mathrm{h}_{\mathrm{L} 0}\end{array}$ \\
\hline Shah (2008) [45] & $\begin{array}{l}\mathrm{Z}=\left(\frac{1}{\mathrm{x}}-1\right)^{0.8} \operatorname{Pr}^{0.4} \\
\mathrm{~h}_{\mathrm{LS}}=0.023 \operatorname{Re}_{1}^{0.8} \operatorname{Pr}_{1}^{0.4} \\
\mathrm{~h}_{1}=\mathrm{h}_{\mathrm{LS}}\left(\frac{\mu_{1}}{14 \mu_{\mathrm{v}}}\right)^{0.0058+0.557 \operatorname{Pr}}\left[(1-\varepsilon)^{0.8}+\frac{3.8 \alpha^{0.76}(1-\mathrm{x})^{0.04}}{\operatorname{Pr}^{0.38}}\right] \\
\mathrm{h}_{2}=1.32 \operatorname{Re}_{1}^{-1 / 3}\left[\frac{\mathrm{g} \rho_{1}\left(\rho_{1}-\rho_{\mathrm{v}}\right) \lambda_{1}^{3}}{\mu_{1}^{2}}\right]^{1 / 3} \\
\text { In regime I: } \mathrm{J}_{\mathrm{v}} \geq \frac{1}{2.4 \mathrm{Z}+0.73} \\
\mathrm{~h}=\mathrm{h}_{1} \\
\text { In regime II: } 0.89-0.93 \exp \left(-0.087 \mathrm{Z}^{-1.17}\right) \geq \mathrm{J}_{\mathrm{v}} \geq \frac{1}{2.4 \mathrm{Z}+0.73} \\
\mathrm{~h}=\mathrm{h}_{1}+\mathrm{h}_{2} \\
\text { For horizontal tubes, the equation is recommended only if } \operatorname{Re}_{\mathrm{TP}}>35,000 \\
\text { In regime II: } \mathrm{J}_{\mathrm{v}} \leq 0.89-0.93 \exp \left(-0.087 \mathrm{Z}^{-1.17}\right) \\
\mathrm{h}=\mathrm{h}_{2}\end{array}$ \\
\hline
\end{tabular}

\subsection{In-Pipe Condensation Modelling with One-Dimensional Codes}

One-dimensional thermal hydraulic system codes are widely used in nuclear safety assessment. They are well developed for water-cooled but also other reactor types and are equipped with two-phase flow models to calculate thermal hydraulic parameters of a reactor system during normal operation, transients and accidents. Typical are two-fluid, five or six-equation models for mass, momentum and energy balancing. The differential equations are coupled and solved with constitutive laws on a set of connected blocks that model axial sections of system components. Compared to CFD codes one-dimensional codes are faster in computation but less accurate for components with pronounced $3 \mathrm{D}$ features, such as e.g., larger vessels. In the following section the modelling of condensation is exemplarily discussed for three widely used system codes ATHLET, RELAP and TRACE.

\subsubsection{ATHLET}

The code package $\mathrm{AC}^{2}$ of the German Gesellschaft für Anlagen- und Reaktorsicherheit (GRS) $\mathrm{GmbH}$ has been developed for simulation of all operational states, incidents, accidents and severe accidents in a nuclear power plant and consists of the code modules ATHLET, ATHLET-CD and COCOSYS. The module ATHLET (Analysis of Thermal-hydraulics of Leaks and Transients) has been developed for the simulation of design basis and beyond design basis accidents (without core degradation) in light water reactors (LWR), including VVER and RBMK reactors. The currently latest release version of ATHLET within $\mathrm{AC}^{2}$ is ATHLET 3.1A [47].

ATHLET is equipped with a heat transfer package comprising several heat transfer correlations. Each heat transfer package activates under various modes on the basis of enthalpy quality $x_{H}$ (Equation (1)) and void fraction $\varepsilon$, as described in the following. 
Mode $1\left(x_{\mathrm{H}} \leq-0.05\right)$ considers single phase convection and the heat transfer coefficient is calculated from the Dittus-Boelter correlation [48](Equation (2)). Constants are $C=0.023, \mathrm{n}=0.4$ for a heating surface and $n=0.3$ for a cooling surface:

$$
\begin{gathered}
\mathrm{x}_{\mathrm{H}}=\frac{\mathrm{H}_{\text {tot }}-\mathrm{H}_{1}}{\mathrm{H}_{\text {evap }}} . \\
\mathrm{h}=\mathrm{C} \frac{\lambda}{\mathrm{D}_{\mathrm{h}}} \operatorname{Re}^{0.8} \operatorname{Pr}^{\mathrm{n}} .
\end{gathered}
$$

The McAdams [49] equation is applied for natural convection, based on the Grashof number Gr:

$$
\begin{gathered}
\mathrm{h}=0.15 \frac{\lambda}{\mathrm{D}_{\mathrm{h}}}(\mathrm{GrPr})^{0.33}\left\{\left[1+(2 \mathrm{Pr})^{-0.5625}\right]\right\}^{-0.5926}, \\
\mathrm{Gr}=\frac{\rho^{2} \mathrm{~g}\left|\mathrm{~T}_{\mathrm{w}}-\mathrm{T}\right| \beta \mathrm{D}_{\mathrm{h}}{ }^{3}}{\mu^{2}} .
\end{gathered}
$$

The parameters $\beta, D_{h}$ and $T_{w}$ represent coefficient of expansion, hydraulic diameter and wall temperature, respectively.

Mode $2\left(-0.05<\mathrm{x}_{\mathrm{H}}<0\right)$ is called the transition region and the heat transfer coefficient is derived via a cosine shape interpolation between the heat transfer coefficients of Mode 1 and Mode 3.

Mode $3\left(0<\mathrm{x}_{\mathrm{H}}\right.$ and $\left.0.995<\varepsilon\right)$ is for film condensation. For laminar film condensation there are three different models, which are described in the following. From these, the maximum heat transfer coefficient value is taken.

Nusselt correlation [50] dependent on the length of the heat transfer surface (L):

$$
\mathrm{h}=\frac{\lambda_{\mathrm{l}}}{\mathrm{e}}\left(\frac{\mathrm{T}_{\mathrm{sat}}-\mathrm{T}_{\mathrm{w}}}{\mathrm{T}_{\mathrm{v}}-\mathrm{T}_{\mathrm{w}}}\right),
$$

with:

$$
\begin{gathered}
\mathrm{e}=\max \left(\mathrm{e}_{1}, \quad \mathrm{e}_{2}, \quad 10^{-10} \mathrm{~m}\right), \\
\mathrm{e}_{1}=1.0606\left[\frac{\rho_{1}\left(\rho_{1}-\rho_{\mathrm{v}}\right) \mathrm{g} \Delta \mathrm{i}_{\mathrm{lv}}\left(1+0.68 \frac{\mathrm{c}_{\mathrm{p}, 1}\left(\mathrm{~T}_{\mathrm{v}}-\mathrm{T}_{\mathrm{w}}\right)}{\Delta \mathrm{i}_{\mathrm{lv}}}\right)}{\lambda_{1} \mu_{1} \mathrm{~L}\left(\mathrm{~T}_{\mathrm{v}}-\mathrm{T}_{\mathrm{w}}\right)}\right], \\
\mathrm{e}_{2}=0.5 \mathrm{D}_{\mathrm{h}}(1-\sqrt{\varepsilon}) .
\end{gathered}
$$

Nusselt correlation [50] determined by condensation flow rate:

$$
\mathrm{h}=1.47 \lambda_{\mathrm{l}} \operatorname{Re}_{1}^{-\frac{1}{3}}\left[\frac{\mu_{1}^{2}}{\rho_{1}\left(\rho_{1}-\rho_{\mathrm{v}}\right) \mathrm{g}}\right]^{-\frac{1}{3}} \frac{\mathrm{T}_{\mathrm{sat}}-\mathrm{T}_{\mathrm{w}}}{\mathrm{T}_{\mathrm{v}}-\mathrm{T}_{\mathrm{w}}}
$$

with:

$$
\operatorname{Re}_{\mathrm{l}}=\frac{\mathrm{G}_{\mathrm{l}} \mathrm{D}_{\mathrm{h}}}{\mu_{\mathrm{l}}}
$$

where:

$$
\begin{gathered}
\operatorname{Re}_{1}<10 \rightarrow \operatorname{Re}_{1}=10, \\
\operatorname{Re}_{1}>2.3 \cdot \mathrm{e}^{3} \rightarrow \operatorname{Re}_{1}=2.3 \cdot \mathrm{e}^{3} .
\end{gathered}
$$

The correlation of Chato [35] is applied as explained in Table 3. 
In the case of turbulent film condensation, ATHLET uses the correlation of Carpenter and Colburn [51], which bases on the analogy between interfacial momentum and heat transfer:

$$
\mathrm{h}=0.065 \frac{\rho_{1}^{0.5}}{\mu_{1}} \operatorname{Pr}_{1}^{0.5} \tau^{0.5} \lambda_{1} \frac{\mathrm{T}_{\mathrm{sat}}-\mathrm{T}_{\mathrm{w}}}{\mathrm{T}_{\mathrm{v}}-\mathrm{T}_{\mathrm{w}}}
$$

For modelling the turbulent film condensation inside horizontal and nearly horizontal tubes (as is the case for EC tubes), the correlation of Dobson and Chato (DC) is applied [40] (Table 3).

\subsubsection{RELAP5/Mod 3.3}

The first version of the Reactor Excursion and Leak Analysis Program (RELAP) code was developed in 1966 at Idaho National Laboratory (INL) and was called RELAPSE [52]. Subsequently, RELAP2, RELAP 3 and RELAP 4 were released, which were all based on a homogenous equilibrium model for two-phase flows. In 1982, RELAP5 was released which contains a two-fluid, non-equilibrium, nonhomogeneous six-equation model. RELAP5/MOD3.3 was released in 2001 for analysis of all transient accidents in LWRs including small and large break LOCA scenarios as well as loss of feedwater, loss of offsite power and station black out [53].

RELAP assumes single-phase convection when void fraction is lower than $10 \%$ and applies the Dittus-Boelter correlation, Equation (2) (as in ATHLET) for turbulent convection. In case of a laminar single-phase convection an exact solution for fully developed laminar flow at $\mathrm{Nu}=4.36$ is used ([54]).

For higher void fractions, condensation models are applied. Turbulent film condensation is modeled by the correlation of Shah, Table 3. The Nusselt equation [36] is used in RELAP for calculating the laminar film condensation as a function of film thickness $(\delta)$ and thermal conductivity $\left(\lambda_{1}\right)$ :

$$
\begin{gathered}
h=\frac{\lambda_{1}}{\delta}, \\
\delta=\left(\frac{3 \mu_{1} G_{1}}{g \rho_{1} \Delta \rho}\right)^{\frac{1}{3}} .
\end{gathered}
$$

\subsubsection{TRACE}

TRAC/RELAP Advanced Computational Engine (TRACE) was released by the U.S. Nuclear Regulatory Commission (NRC). It maintains all the capabilities of previous system codes RELAP 5, RAMONA, TRAC-PWR and TRAC-BWR [55]. TRACE is a finite-volume based two-fluid model code for compressible flows which is able to model large and small break LOCA scenarios and system transients in both PWRs and BWRs. This code has the capability of modelling thermal hydraulic phenomena in both one-dimensional and three-dimensional space.

Contrary to RELAP, in TRACE the film condensation model is applied when the void fraction is higher than $90 \%$ while for void fractions lower than $80 \%$ a two-phase convection is assumed. The range between $80 \%$ and $90 \%$ is assumed as a transition region and an interpolation is made.

For the two-phase convection, TRACE applies a multiplier to the single phase heat transfer models accounting for the two-phase flow effects. For laminar convection, similar to RELAP, the Nusselt number is set to $\mathrm{Nu}=4.36$. For turbulent convection, the heat transfer coefficient of Gnielinski [56] is implemented (Equation (14)), following recommendations by Bhatti et al. [57] and Incropera et al. [58]. This correlation is valid for the transition region $(1000<\operatorname{Re}<3000)$ :

$$
\mathrm{h}=\frac{\mathrm{f} / 2(\operatorname{Re}-100) \operatorname{Pr}}{1+12.7(\mathrm{f} / 2)^{0.5}\left(\operatorname{Pr}^{2 / 3}-1\right)} \lambda_{\mathrm{l}}\left(\frac{\mu_{\mathrm{l}}^{2}}{\mathrm{~g} \rho_{\mathrm{l}}\left(\rho_{\mathrm{l}}-\rho_{\mathrm{v}}\right)}\right)^{-\frac{1}{3}},
$$

with the friction factor:

$$
f=(1.58 \ln (\operatorname{Re})-3.28)^{-2}
$$


In case of natural convection, a maximum value between the laminar and the turbulent heat transfer coefficients is used [59]:

$$
\begin{aligned}
h_{\text {lam }} & =\frac{\lambda_{1} 0.1\left(\mathrm{Gr}_{1} \operatorname{Pr}_{1}\right)^{1 / 8}}{\mathrm{D}}, \\
\mathrm{h}_{\text {turb }} & =\frac{\lambda_{1} 0.59\left(\mathrm{Gr}_{1} \mathrm{Pr}_{1}\right)^{1 / 4}}{\mathrm{D}},
\end{aligned}
$$

where the parameter $\mathrm{D}$ is a characteristic length.

The film condensation model is specified according to the Reynolds number. If $\operatorname{Re}<2$, a smooth laminar film condensation is assumed and the Nusselt number is set to unity. For $\operatorname{Re} \geq 20$, occurrence of waves on the film interface is assumed, which is modelled by the empirical correlation of Kuhn et al. [60] for laminar-wavy falling film condensation:

$$
\mathrm{h}=\frac{2 \cdot \lambda_{1}}{\delta}\left(1+1.83 \mathrm{e}^{-4} \operatorname{Re}_{1}\right)
$$

the film thickness $(\delta)$ is derived from the void fraction and hydraulic diameter $\left(D_{h}\right)$ as:

$$
\delta=\frac{\mathrm{D}_{\mathrm{h}}(1-\sqrt{\varepsilon})}{2} .
$$

The turbulent condensation is modeled according to Gnielinski [56] (Equation (14)) with a multiplying factor of $\frac{1}{4}$.

\subsubsection{Application and Assessment of 1D Codes for Passive Safety Systems Analyses}

A number of numerical investigations have been performed with respect to assessment of current heat transfer packages in aforementioned $1 \mathrm{D}$ codes and subsequently proposing new correlations to improve them. They will be briefly discussed in the following.

Schaffrath developed the KONWAR model in ATHLET on the basis of emergency condenser experiments carried out at the NOKO test facility at Research Center Jülich [61,62]. KONWAR is a semi-empirical heat transfer package based on the flow pattern map of Tandon et al. [33]. Although KONWAR was successfully validated against the NOKO experiments, it has to be considered that the utilized flow pattern map of Tandon et al. is originally based on data obtained by experiments with the refrigerants R-12 and R-133 in tubes with internal diameters ranging from $4.8 \mathrm{~mm}$ to 15.9 $\mathrm{mm}$. Later on, Schaffrath et al. [63] validated the KONWAR model with data from the HORUS test facility [64] and results showed good agreement.

Choi et al. [65] analyzed and improved the standard condensation models in RELAP5/MOD 3.2. They concluded that the standard laminar film condensation model overestimates heat transfer in regions with higher heat transfer while it underestimates in regions with lower heat transfer compared to experimental data. They found that for turbulent film condensation modeling, the Shah correlation results in good agreement with experimental data. Moreover, for both counter-current and co-current experimental data, RELAP5 overpredicts the heat transfer value. Later on, Choi et al. [66] improved the model significantly by substituting the Dittus-Boelter correlation by a correlation from Kim [67] and use of a multiplier factor.

The condensation models of RELAP5 were assessed by Zhou et al. [68] by modelling condensation in a single tube and a tube bundle similar to the one in the passive containment condenser system (PCCS). Their results showed a high discrepancy compared to data from experiments conducted at Purdue University. Macedo et al. [69] performed experimental and numerical investigations on the effect of non-condensable gases during steam condensation in horizontal tubes for pressure values between 200 to $400 \mathrm{kPa}$. The comparison revealed an overestimation of the heat transfer for higher pressures. Later on, Aglar [70] further analyzed the effects of non-condensable gases on in-tube condensation and compared simulations with three experimental test facilities data. They found 
that RELAP5 has a deviation in the range of $50 \%$ to $150 \%$ for the heat transfer coefficient. Another finding was that the simulation accuracy decreases significantly with increasing air-steam mixture Reynolds number.

Szijártó et al. [71] performed simulations of a fast transient condensation process in slightly inclined tubes with the original RELAP5 code and compared the results with data from the INVEP [72] experiment. They found high overestimation of calculated pressure, temperature and void fraction compared to the INVEP data. Later on, Szijártó et al. [73] proposed a new mechanistic model that considers the flow regime in three regions: laminar film condensation on the upper part, turbulent condensation on the bottom part and steam in the core of the tube. This new model does predict the heat transfer coefficient significantly better.

Lee et al. [74] assessed the applicability of the TRACE code for modelling of condensation inside nearly horizontal tubes and compared the result with the one of the KAERI PASCAL test facility. They concluded that the TRACE code approximately $30 \%$ overestimates the heat flux values. Moreover, Pollman et al. [75] performed TRACE simulations of rapid condensation transient at the MANTOTEA facility and found that simulations overestimate the pressure and the temperature in the condenser tubes.

\subsection{CFD Modelling}

As introduced in Section 2.3, system codes use section-averaged values for prediction of flow characteristics and heat transfer. For this reason, they have limitations for flows with pronounces 3D effects, that is, in components with complex geometry or in cases with a complex two-phase flow structure. In principle, CFD codes are able to account for more complex flow characteristics and heat transfer by solving the governing mass, momentum and energy equations in 3D. However, the state of the art in CFD is not yet mature for two-phase flows due to the complex gas-liquid interface and complex interactions between the phases. In the following, we give a review of heat transfer correlations that are being used with CFD codes in different multiphase flow approaches such as the one-fluid volume of fluid model (VOF), level set, and the Euler-Euler two-fluid approach.

To consider phase change in two-phase flows source terms have to be defined in the balance equations. The energy source term results from the mass transfer rate $\mathrm{G}$ and the latent heat $\Delta \mathrm{i}_{\mathrm{lv}}$ :

$$
\mathrm{q}^{\prime \prime}=\mathrm{G} \cdot \Delta \mathrm{i}_{\mathrm{lv}}
$$

One of the first attempts to model the mass transfer rate was made by Lee et al. [76]. He considered the interface between liquid and steam at saturation temperature and introduced an iterative technique to reach this condition. If a cell at the liquid-steam interface has a temperature that is not equal to saturation temperature, mass transfer is activated. The transfer rate is calculated as:

$$
\Gamma=\left\{\begin{array}{c}
-r \varepsilon_{1} \rho_{1} \frac{T-T_{\text {sat }}}{T_{\text {Sat }}} \text { if } T\left\langle\mathrm{~T}_{\text {sat }} \text { and }\left|\nabla \varepsilon_{\mathrm{V}}\right|\right\rangle 0, \\
-r \varepsilon_{\mathrm{v}} \rho_{\mathrm{v}} \frac{\mathrm{T}_{\text {sat }}-\mathrm{T}}{\mathrm{T}_{\text {sat }}} \text { if } T\left\langle\mathrm{~T}_{\text {sat }} \text { and }\left|\nabla \varepsilon_{\mathrm{v}}\right|\right\rangle 0 .
\end{array}\right.
$$

The mass transfer rate depends on a relaxation factor $r$ that needs to be tuned. The tuning requires many trial and error simulations, which is time-consuming and must be done for each case separately. Several groups, such as Da Riva et al. [77], applied the Lee model (Equation (21)) for simulation of laminar liquid film condensation in a horizontal circular microchannel with the VOF method. Qiu et al. [78] conducted a transient VOF simulation of the condensation in an upward flow of wet steam. Liu et al. [79] investigated the laminar liquid film generation and its effect on heat transfer with the VOF model. Szijarto et al. [80] used the VOF model to simulate direct contact condensation at steam-liquid interface for the LAOKOON experiment facility [81]. The main conclusion from all these investigations is that lower values of the parameter $r$ lead to a significant underestimation of the calculated heat transfer while too high values results in numerical convergence problems. Therefore, 
the optimal value for $r$ depends mainly on the specific case and can vary as much as between $100 \mathrm{~s}^{-1}$ and $750,000 \mathrm{~s}^{-1}$.

Due to the neglect of the phase change in the original VOF two-phase flow [82,83], Welch et al. [84] introduced a numerical method to determine heat flux vectors $\vec{q}$ on each side of the interface in conjunction with VOF. The mass flux source term $\mathrm{q}^{\prime \prime} / \Delta \mathrm{i}_{\mathrm{lv}}$ is derived from the difference between the components of the velocity vectors, which are normal to the interface:

$$
\left(\vec{u}_{v}-\vec{u}_{i}\right) \cdot \vec{n}-\left(\vec{u}_{v}-\vec{u}_{i}\right) \cdot \vec{n}=\left(\frac{1}{\rho_{1}}-\frac{1}{\rho_{v}}\right) \frac{q^{\prime \prime}}{\Delta i_{l v}}
$$

Zhaohui et al. [85] calculated condensation induced water-hammers caused by cavity collapse using the VOF model. They used a phase change model derived from the kinetic theory of gases by Collier et al. [50]. There, phase change mass flow rate is given as:

$$
\Gamma=\left(\frac{\mathrm{M}_{\mathrm{r}}}{2 \pi \mathrm{R}_{\mathrm{g}}}\right)^{\frac{1}{2}}\left[\frac{\mathrm{P}_{\mathrm{v}}}{\mathrm{T}_{\mathrm{v}}^{\frac{1}{2}}}-\frac{\mathrm{P}_{1}}{\mathrm{~T}_{1}^{\frac{1}{2}}}\right] \frac{2 \mathrm{~b}}{2-\mathrm{b}^{\prime}}
$$

where $\mathrm{M}_{\mathrm{r}}$ is the relative molecular mass, $\mathrm{R}$ is the universal gas constant and the condensation coefficient $\mathrm{b}$ is assumed between 0.03 and 0.05 .

For modelling of direct contact condensation (DCC) on the liquid-steam interface several correlations have been developed. Strubelj et al. [86] simulated condensation-induced water hammer in a steam-filled horizontal pipe that was gradually filled with subcooled water using the two-fluid approach within NEPTUNE_CFD [87] and ANSYS CFX code. They assumed the steam at saturation temperature, which gives the interphase mass flow rate per unit interfacial area as:

$$
\mathrm{G}=\frac{\mathrm{h}_{1}\left(\mathrm{~T}_{\mathrm{sat}}-\mathrm{T}_{1}\right)}{\Delta \mathrm{i}_{\mathrm{lv}}}
$$

Several authors proposed empirical correlations for the liquid heat transfer coefficient for DCC as a function of Reynolds and Prandtl number. Hughes et al. [88] developed a heat transfer correlation on the basis of surface renewal theory (SRT) and Kolmogorov turbulent length scale. In the surface renewal theory, mass transfer is defined as a function of renewal period of eddies which is related to turbulence parameters. The bulk liquid, which is below the saturation temperature, is transported to the surface by turbulent eddies and the saturated condensate flow is taken away from the interface. The Hughes model assumes that the removal of heat from the liquid-steam interface is determined by the smallest turbulence scales in the flow. In this model, the heat transfer coefficient of liquid is:

$$
\mathrm{h}_{1}=\frac{2}{\sqrt{\pi}} \lambda_{1} \operatorname{Pr}_{1}^{\frac{1}{2}}\left(\frac{\epsilon}{\mathrm{v}_{1}}\right)^{\frac{1}{4}} .
$$

Egorov et al. [89] used the Hughes correlation for validation of CFD codes with PTS-relevant test cases. Apanasevich et al. [90] simulated heat and mass transfer at the interface of stratified two-phase flow using a two-fluid model and Hughes correlation and validated the model with TOPFLOW-PTS steam/water experiments.

Shen et al. [91] developed a correlation based on SRT in a similar way to the one from Hughes (Equation (25)). However, it considers that larger eddies are responsible for heat transport from the 
liquid surface. This model leads to a longer surface renewal period and respectively a slower heat removal from the interface. In this model the liquid heat transfer coefficient is calculated as:

$$
\mathrm{h}_{1}=\frac{1.407}{\sqrt{\pi}} \lambda_{1} \operatorname{Pr}_{1}^{\frac{1}{2}}\left(\frac{\mathrm{C}_{\mu} \mathrm{k}^{\frac{1}{2}}}{\epsilon}\right)^{-\frac{1}{3}}\left(\frac{\mathrm{C}_{\mu}^{\frac{1}{2}}\left(\mathrm{v}_{\mathrm{l}} \epsilon\right)^{\frac{1}{4}}}{\mathrm{v}_{\mathrm{l}}}\right)^{\frac{2}{3}}
$$

Ceuca et al. [92] applied both correlations (Equations (25) and (26)) to simulate DCC with ANSYS CFX using the VOF model. A comparison of calculated temperature profiles with experimental data of the LAOKOON facility [81] is depicted in Figure 7. It shows that both models provide good results for the horizontal stratified quasi-steady state, however, the Hughes model overestimates the water temperature away from the interface.

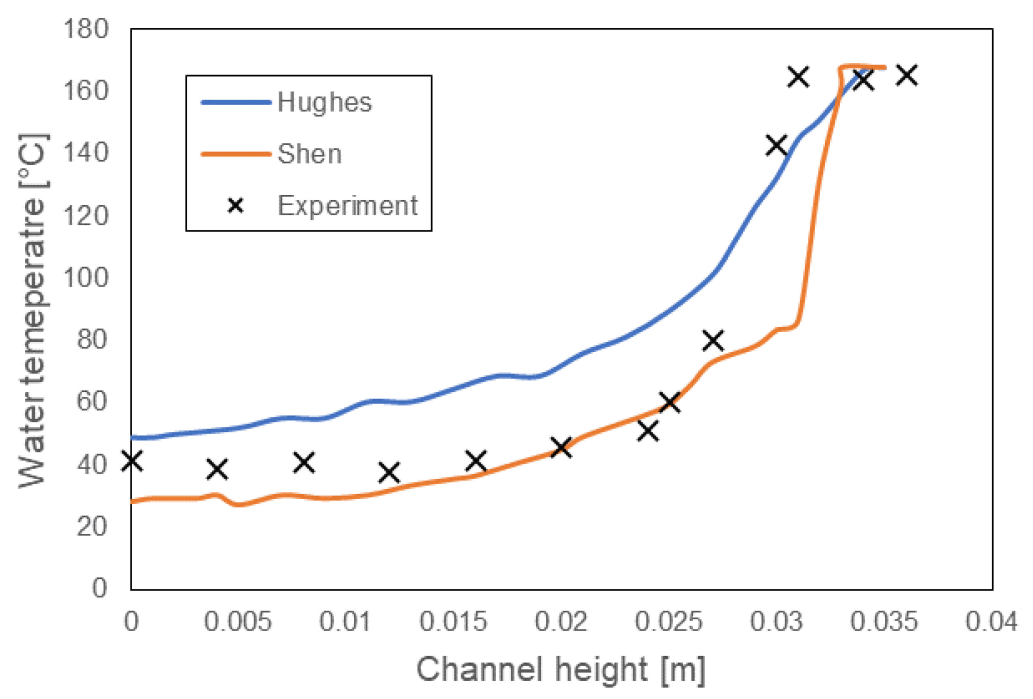

Figure 7. Comparison of temperature profiles of the SRT based models (Shen and Hughes) with LAOKOON experimental data [92].

Banerjee et al. [93] introduced the so-called surface divergence (SD) theory for mass transfer when no gas shear at the interface exists. They used the blocking theory of Hunt et al. [94] to implement the turbulence properties. Later on, Banerjee et al. [95] assessed the SD model for sheared interfaces and compared it with direct numerical simulation (DNS) results. They stated that the SD theory can also be applied for the sheared interfaces. From that, a correlation for the heat transfer rate has been derived as:

$$
\frac{\mathrm{K}}{\mathrm{u}_{\mathrm{t}}} \equiv \frac{\mathrm{G}}{\rho \cdot \mathrm{u}_{\mathrm{t}}}=\operatorname{CPr}^{\mathrm{N}} \mathrm{f}\left[\operatorname{Re}_{\mathrm{t}}\right] \operatorname{Re}_{\mathrm{t}}^{\mathrm{M}},
$$

where $\mathrm{K}$ and $\mathrm{u}_{\mathrm{t}}$ denote the transfer velocity and the turbulent velocity scale. The surface divergence function $\mathrm{f}$ is:

$$
f\left[\operatorname{Re}_{t}\right]=\left[0.3\left(2.83 \operatorname{Re}_{t}^{\frac{3}{4}}-2.14 \operatorname{Re}_{t}^{\frac{2}{3}}\right)\right]^{\frac{1}{4}}
$$

The parameter C in Equation (28) is a model constant and depends on liquid properties, Schmidt number and Prandtl number. Exponents $\mathrm{N}$ and $\mathrm{M}$ depend on the surface conditions and turbulence intensity. The model was further applied by Lakehal et al. [96] for condensing stratified flows and provided good predictions for low and mild interfacial shear.

Zschaeck et al. [97] introduced and validated a model for wall condensation. The fluid is assumed to be a multi-component gaseous mixture with one condensable and at least one non-condensable component. The model neglects the details of the liquid film due to single-phase simulation and the 
mass of the liquid phase, which is generated during the condensation and removed from the system (Figure 8).

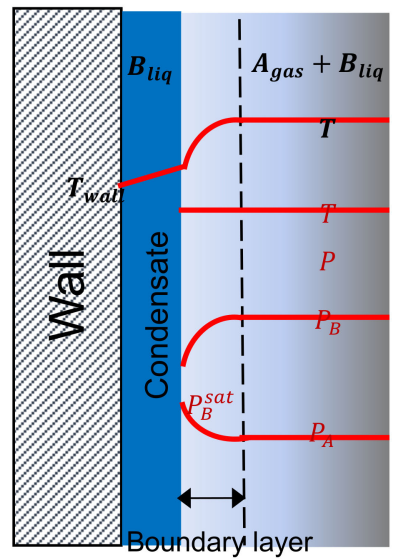

(a)

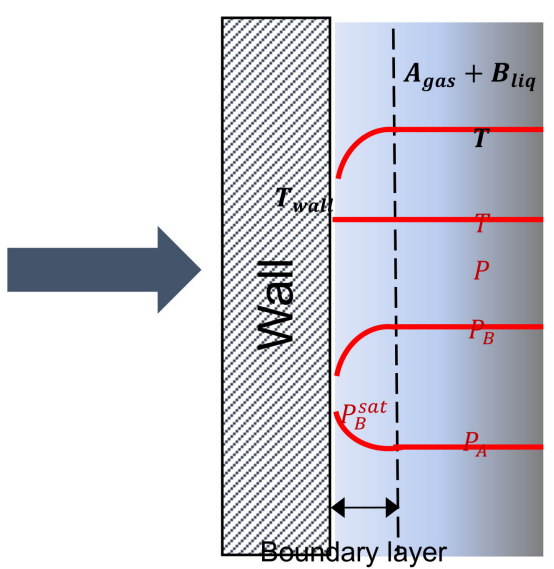

(b)

Figure 8. (a) Condensation process and temperature distribution near the wall region, (b) ANSYS CFX wall condensation model concept [97].

The wall condensation model considers different mass flux values for laminar and turbulent boundary layers. This simple condensation model is implemented in ANSYS CFX and has been validated with different experimental test cases such as from the CONAN test facility [98] and experiments from Kuhn et al. [99,100]. Lehmkuhl et al. [101] and Müller et al. [102] used this model and implemented a new wall function for momentum equations to improve computational efficiency for containment applications. Punetha et al. [103] verified it for cases with more than one non-condensable gas such as helium-air mixtures.

\section{Condensation on the Outside of Inclined Tubes}

Further to the condensation inside ECs, which has been discussed in Section 2, the second essential stage in the heat transfer chain of the passive heat removal system of KERENA is the condensation heat transfer at the containment cooling condensers (CCC). For that, two types of wall condensation on inclined tubes have to be distinguished: film condensation and dropwise condensation. Dropwise condensation benefits from higher heat transfer coefficients, however, film condensation occurs more often in industrial applications. Therefore, models concerning dropwise condensation are rarely developed. In the following, film and dropwise condensation models on inclined tubes are presented. Similar to Section 2, a review of models developed on the basis of experimental data is presented first. Afterwards, numerical models for system codes are discussed. As CFD models are geometry independent and local the same models as discussed in Section 2.4 can be applied.

\subsection{Correlations Obtained from Experiments}

One of the first proposed correlations for dropwise condensation is from Le Fevre and Rose [104,105]. They assumed hemispherical drops with a constant temperature. According to the experimental data and considering the effects of surface curvature, they approximated the mean heat flux $\mathrm{q}_{\mathrm{b}}{ }_{\mathrm{b}}$ through a hemispherical drop with radius $\mathrm{r}$ as:

$$
\mathrm{q}^{\prime \prime}{ }_{\mathrm{b}}=\frac{4 \lambda_{\mathrm{d}}}{\pi \mathrm{r}}\left(\Delta \mathrm{T}-\frac{2 \sigma \mathrm{V}_{\mathrm{d}} \mathrm{T}_{\mathrm{sat}}}{\mathrm{r} \rho_{\mathrm{d}} \Delta \mathrm{i}_{\mathrm{lv}}}\right) \ln \left\{1+\alpha\left(1.09+\frac{\frac{\pi}{2}-1.09}{\frac{\alpha}{5.7}-1}\right)\right\},
$$


where parameters $V_{d}$ and $\sigma$ represent the specific volume of the condensate drop and the surface tension, respectively. The parameter $\alpha$ is defined as:

$$
\alpha=\frac{h_{\mathrm{i}} \mathrm{r}}{\lambda_{\mathrm{d}}} .
$$

The interfacial heat transfer coefficient $h_{i}$ is derived from the kinetic theory as a function of heat capacity ratio $K$ and gas constant $R_{g}$ :

$$
h_{i}=\left(\frac{\kappa-1}{\kappa+1}\right) \frac{\Delta \mathrm{i}_{\mathrm{lv}}{ }^{2} \rho_{\mathrm{v}}}{\mathrm{T}_{\mathrm{v}}}\left(\frac{2 \pi}{\mathrm{R}_{\mathrm{g}} \mathrm{T}_{\mathrm{v}}}\right)^{0.5}
$$

Finally, the mean heat flux for dropwise condensation is calculated by integrating Equation (29) weighted by the drop size distribution $\mathrm{A}(\mathrm{r})$ between the minimum drop radius $\mathrm{r}_{t}$ and the maximum radius $\hat{r}$ :

$$
\begin{gathered}
\mathrm{q}^{\prime \prime}=\int_{\mathrm{r}_{\mathrm{t}}}^{\hat{\mathrm{r}} \mathrm{q}_{\mathrm{b}}{ }_{\mathrm{b}} \mathrm{A}(\mathrm{r}) \mathrm{dr},} \\
\mathrm{A}(\mathrm{r})=\frac{1}{\mathrm{r}}\left[0.871\left(\frac{\mathrm{r}}{\hat{\mathrm{r}}}\right)^{0.5}-1.39\left(\frac{\mathrm{r}}{\hat{\mathrm{r}}}\right)+1.296\left(\frac{\mathrm{r}}{\hat{\mathrm{r}}}\right)^{2}\right] .
\end{gathered}
$$

The minimum drop radius is defined as $r_{t}=\frac{2 \sigma V_{d} T_{v}}{\Delta i_{l_{v}} \Delta T}$ and the maximum drop radius is assumed as $1 \mathrm{~mm}$ (as found in experimental observations). Rose compared his theory with experimental data, Figure 9. Line (a) shows the results from the original Rose model, Equation (33). Since the agreement is not satisfying, Rose made several modifications. For line (b), the minimum droplet radius in the drop size distribution (Equation (32)) has been set to 10 $r_{t}$. The model line (c) stand for a model derivative with $\Delta \mathrm{T}$ in Equation (29) being replaced by $\Delta \mathrm{T}-\mathrm{q}^{\prime \prime}{ }_{\mathrm{b}} \mathrm{R}_{\mathrm{p}}$, where $\mathrm{R}_{\mathrm{p}}=\delta_{\mathrm{p}} / \lambda_{\mathrm{p}}$ accounts for a promoter layer resistance $\left(\delta_{p}\right.$ and $\lambda_{p}$ represent thickness and thermal conductivity of the promoter layer). Line (d) represents again a modification regarding the drop size distribution, where the maximum droplet size is set to $\hat{r}=1.75 \mathrm{~mm}$ [105]. For this analysis Rose used numerous experimental databases from different investigations [105].

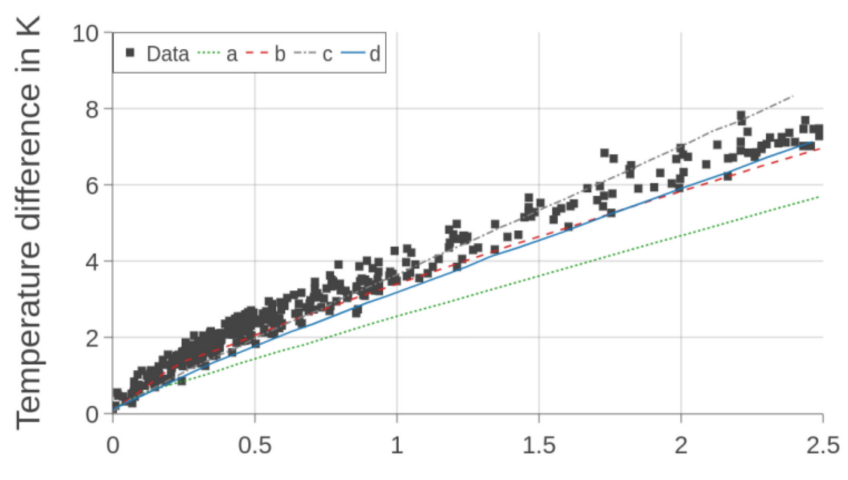

Heat flux in $\mathrm{MW} / \mathrm{m}^{2}$

Figure 9. Comparison of the correlation by Rose with experimental data (line a) and modification of the correlation (line b, $c$ and d) [105].

Bonner [106] applied the theory of Rose to develop advanced models for dropwise condensation. He introduced a model that is independent from heat flux:

$$
\mathrm{h}=33 \frac{\lambda}{\mathrm{r}_{\mathrm{d}}{ }^{2 / 3} \mathrm{r}_{\mathrm{i}}{ }^{1 / 3}}\left(\frac{\sin \vartheta}{1-\cos \vartheta}\right)
$$


and one that depends on it:

$$
\mathrm{h}=2.7 \frac{\lambda}{\mathrm{r}_{\mathrm{d}}^{1 / 2} \mathrm{r}_{\mathrm{i}}^{1 / 4} \mathrm{r}_{\mathrm{t}}^{1 / 4}}\left(\frac{\sin \vartheta}{1-\cos \vartheta}\right)
$$

Parameters are the contact angle $\vartheta$, the radius of a departing droplet $r_{d}$, the effective length between the interfacial resistance (caused by mass transfer) and droplet conduction resistance $r_{i}$, and the minimum droplet size $r_{t}$. Furthermore, both models take the inclination angle $\gamma$ into account (Equation (36)). These parameters are defined as follows:

$$
\begin{gathered}
\mathrm{r}_{\mathrm{d}}=\left(\frac{\sigma}{\rho \mathrm{g} \sin \gamma}\right)^{1 / 2}, \\
\mathrm{r}_{\mathrm{i}}=\frac{\lambda \mathrm{T}_{\mathrm{sat}}}{\rho_{\mathrm{v}} \Delta \mathrm{i}_{\mathrm{lv}}^{2}}\left(\frac{\sin \vartheta}{1-\cos \vartheta}\right)\left(\frac{\kappa+1}{\kappa-1}\right)\left(\frac{\mathrm{R}_{\mathrm{g}} \mathrm{T}_{\mathrm{sat}}}{2 \pi}\right)^{\frac{1}{2}}, \\
\mathrm{r}_{\mathrm{t}}=\frac{2 \sigma \mathrm{T}_{\mathrm{sat}}}{\rho \Delta \mathrm{i}_{\mathrm{lv}} \Delta \mathrm{T}} .
\end{gathered}
$$

Bonner compared the heat flux dependent and independent model with experimental data provided by Stylianou, which also served for Rose's model, [106] Figure 10. Both of the correlations are in a good agreement with experimental data, however, the heat flux dependent one can predict the trend of experimental results better than the other.

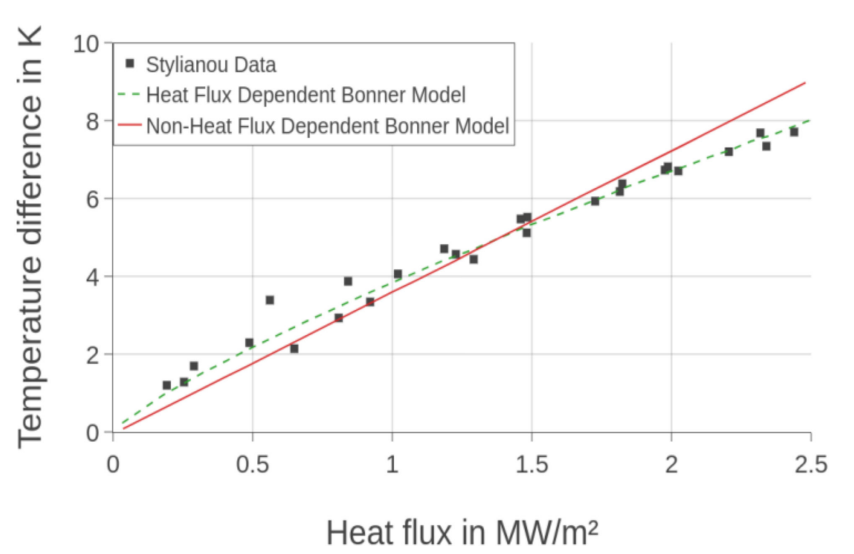

Figure 10. Comparison of the heat flux dependent (Bonner I) and heat flux independent (Bonner II) model with experimental data provided by Stylianou [106].

Browne et al. [107] assessed Nusselt equations for film condensation on inclined tubes and stated that they result in satisfying agreement for smooth tubes compared to experimental data. The Nusselt equations for laminar (Equation (39)) and turbulent (Equation (40)) film condensation [50] are derived as Nusselt-laminar film condensation:

$$
\mathrm{h}=0.725\left(\frac{\rho_{\mathrm{l}}\left(\rho_{\mathrm{l}}-\rho_{\mathrm{v}}\right) \mathrm{g} \Delta \mathrm{i}_{\mathrm{lv}}\left(1+0.68 \frac{\mathrm{c}_{\mathrm{p}, \mathrm{l}}\left(\mathrm{T}_{\mathrm{sat}}-\mathrm{T}\right)}{\Delta \mathrm{i}_{\mathrm{lv}}}\right) \lambda_{\mathrm{l}}^{3}}{\mathrm{D}_{\mathrm{h}} \mu_{\mathrm{l}}\left(\mathrm{T}_{\mathrm{sat}}-\mathrm{T}_{\mathrm{W}}\right)}\right)^{0.25} .
$$

Nusselt-turbulent film condensation:

$$
\mathrm{h}=0.056\left(\frac{4 \cdot \Gamma}{\mu_{1}}\right)^{0.2}\left(\frac{\rho_{1}\left(\rho_{1}-\rho_{\mathrm{v}}\right) g c_{\mathrm{p}, 1}}{\mu_{1}}\right)^{\frac{1}{3}} \lambda_{1}^{\frac{2}{3}} .
$$




\subsection{Outside Condensation Modelling with One-Dimensional Codes}

The 1D system codes ATHLET, RELAP and TRACE apply models for film condensation while only in TRACE, a model for dropwise condensation is implemented $[47,108,109]$. ATHLET applies the same correlations (as discussed in Section 2.3.1) for condensation inside and outside of inclined tubes. The heat transfer correlations in RELAP are selected based on the particular geometry and heat transfer phenomena. The geometries are "inclined surface condensation" and "horizontal bundle with in-line tubes", see Figure 11. The heat transfer for film condensation on an inclined surface (is calculated with the Nusselt equation for a laminar film and with the Shah correlation for a turbulent film [108]. The transition between the flow types is defined at $\operatorname{Re}=1800$.

RELAP-film condensation on an inclined surface:

$$
\begin{gathered}
\mathrm{h}=\max \left(\mathrm{h}_{\text {Nusselt }}, \mathrm{h}_{\text {Shah }}\right), \\
\mathrm{h}_{\text {Nusselt }}=\frac{\lambda_{\mathrm{l}}}{0.9086}\left(\mathrm{~g} \frac{\rho_{\mathrm{l}}\left(\rho_{\mathrm{l}}-\rho_{\mathrm{v}}\right)}{\mu_{1}^{2} \operatorname{Re}_{\mathrm{l}}}\right)^{\frac{1}{3}}, \\
\mathrm{~h}_{\text {Shah }}=0.023\left(\frac{\lambda_{1}}{\mathrm{D}_{\mathrm{h}}}\right) \operatorname{Re}_{1}^{0.8} \operatorname{Pr}_{1}^{0.4}(1-\mathrm{x})^{0.8}\left(1+\frac{3.8}{\left(\left(\frac{1}{\mathrm{x}}-1\right)^{0.8}\left(\frac{\mathrm{p}}{\mathrm{P}_{\text {crit }}}\right)^{0.4}\right)^{0.95}}\right) .
\end{gathered}
$$

For film condensation on a horizontal tube bundle a correlation by Chen [108] is used

$$
\mathrm{h}=0.728\left[1.0+0.2 \frac{\mathrm{c}_{\mathrm{p}, 1} \Delta \mathrm{T}}{\Delta \mathrm{i}_{\mathrm{lv}}}\left(\operatorname{MAX}\left(1, \varphi_{\mathrm{i}} \mathrm{n}\right)-1\right)\right]\left[\frac{\mathrm{g} \rho_{1}\left(\rho_{1}-\rho_{\mathrm{v}}\right) \lambda_{\mathrm{l}}{ }^{3}\left(\Delta \mathrm{i}_{\mathrm{lv}}+0.375 c_{\mathrm{p}, 1} \Delta \mathrm{T}\right)}{\operatorname{MAX}\left(1, \varphi_{\mathrm{i}} \mathrm{n}\right) \mathrm{D}_{\mathrm{h}} \mu_{\mathrm{l}} \Delta \mathrm{T}}\right]^{0.25} .
$$

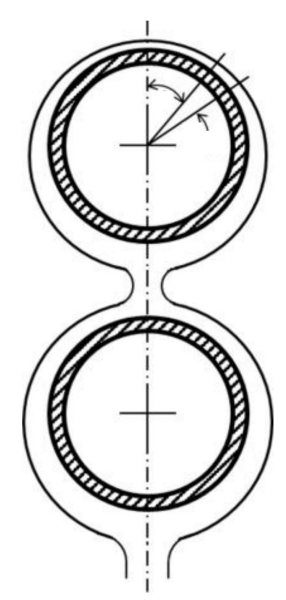

Figure 11. Film condensation on a tube bundle as implemented in RELAP [108].

TRACE also applies the same film condensation models for condensation inside and outside inclined tubes, which were presented in Section 2.3.3. In TRACE only a simple model for dropwise condensation is implemented. The heat transfer (Equation (45)) consists of the heat transfer from the wall to the vapor (Equation (46)) and the heat transfer from the wall to the liquid (Equation (47)) and uses the amount of the wetted surface (Equation (48)) which is based on contact angle $\left(\delta_{\min }\right)$ and hydraulic diameter $\left(D_{h}\right)$ [109]. $h_{\text {film }}$ is derived from film condensation models:

$$
\mathrm{h}=\mathrm{h}_{\mathrm{wv}}+\mathrm{h}_{\mathrm{wl}},
$$




$$
\begin{gathered}
\mathrm{h}_{\mathrm{wv}}=\left(1-\mathrm{f}_{\mathrm{wet}}\right) \frac{\mu_{\mathrm{l}}}{\delta_{\min }}, \\
\mathrm{h}_{\mathrm{wl}}=\mathrm{f}_{\mathrm{wet}} \mathrm{h}_{\mathrm{film}} \\
\mathrm{f}_{\mathrm{wet}}=\frac{(1-\varepsilon) \mathrm{D}_{\mathrm{h}}}{4 \delta_{\min }} .
\end{gathered}
$$

\section{Experimental Test Facilities}

In the last years, several experimental investigations have been conducted to analyse the integral and local performance of the passive heat removal system components of the BWR KERENA reactor. The INtegral test facility KArlstein (INKA) at Framatome GmbH [10] was designed and implemented by Framatome $\mathrm{GmbH}$ to investigate the integral performance of passive safety systems of the KERENA (Figure 12). The INKA facility was constructed with a 1:1 height and a 1:24 volumetric scaling relative to the plant scale. It includes large vessels simulating the KERENA containment and the large water volumes of the storage pool, the core flooding pool, the pressure suppression chamber and one of the four emergency condensers and containment cooling condensers. More than 300 sensors are installed for measuring temperature, mass flow rate, absolute and differential pressure and two-phase flow distribution. The INKA facility is able to conduct the integral and single components studies for different accident scenarios such as breaks in steam-line, RPV bottom leaks as well as station black-out. Furthermore, single effect investigations such as steam flow and condensate level in EC single tubes, influence of non-condensable gases on the heat transfer inside the EC and two-phase instabilities in the CCC, are also possible to conduct. However, the moderate local instrumentation of the larger components does allow a detailed thermal hydraulic analysis of local flow and heat transfer. Therefore, several single component facilities for detailed investigations of the KERENA passive safety systems components have been constructed. In the following some of the most important ones accounting for condensation studies are introduced.

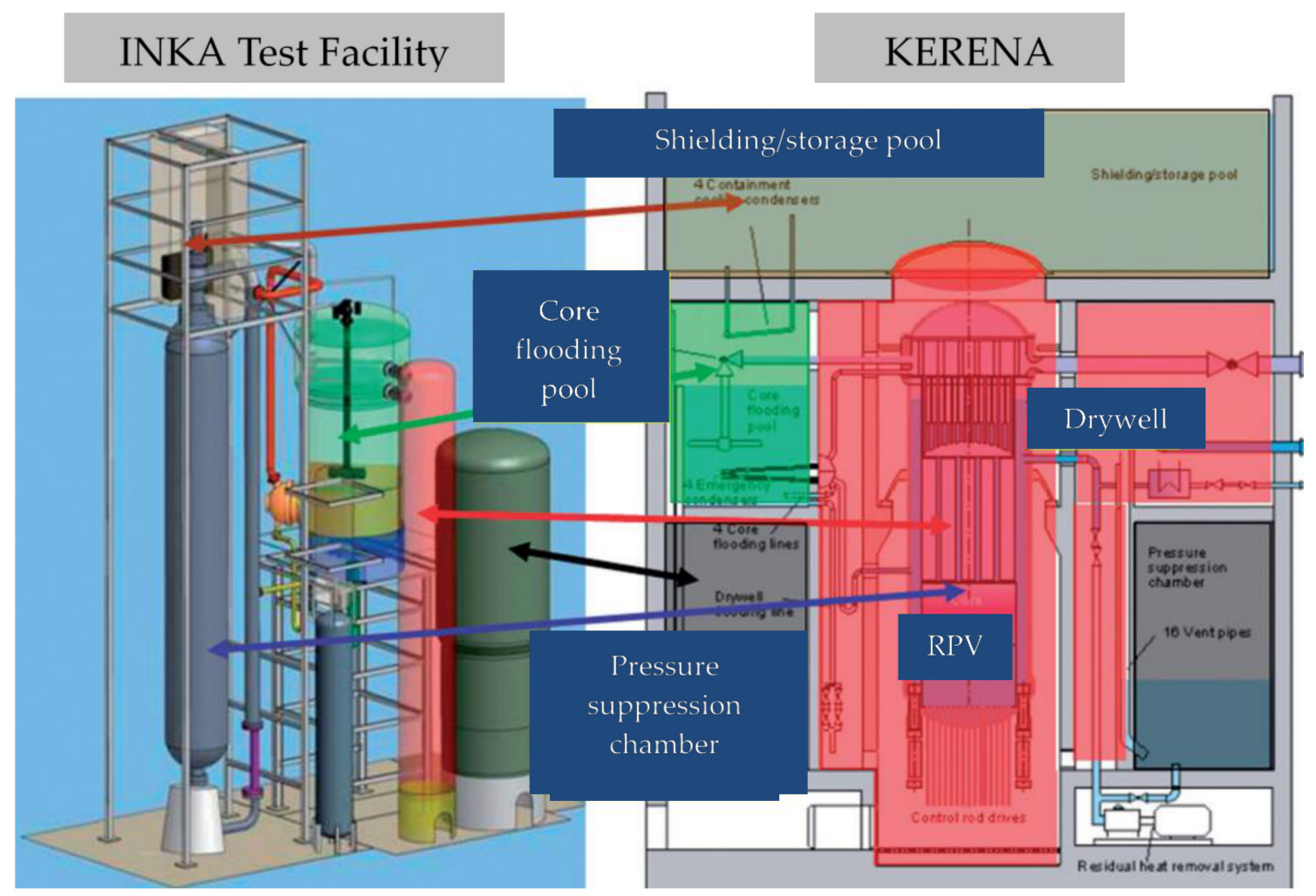

Figure 12. INKA test facility regarding the KERENA reactor concept [10]. 
The NOKO facility (Ger.: NOtKOndensator) was set up at Forschungszentrum Jülich. It models the emergency condensers with a reduced number of eight tubes Figure 13. The NOKO test facility had an operating pressure of up to 100 bar and a maximum of $4 \mathrm{MW}$ steam supply. The emergency condenser bundle was fabricated with the planned geometry and material of the KERENA EC. The NOKO was equipped with several thermocouples and void probes to perform transient measurements of liquid distribution and condensation heat transfer for different experimental conditions, including studies with non-condensable gases. In 2001, it was disassembled and some parts of it transferred to the Transient TwO Phase FLOW Test Facility (TOPFLOW) facility [110] at Forschungszentrum Rossendorf (now Helmholtz-Zentrum Dresden-Rossendorf) for the further studies of phenomena on the secondary (cooling) side.

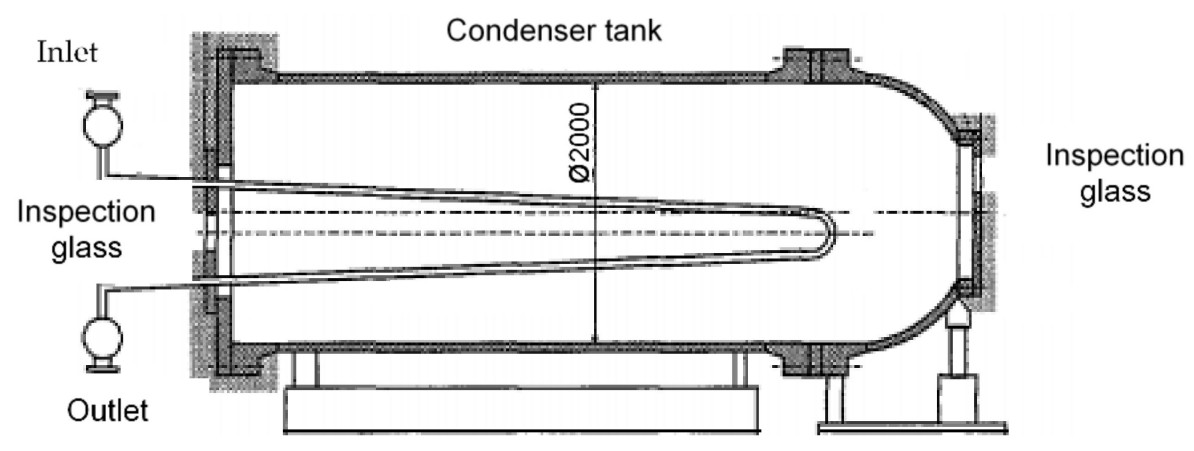

Figure 13. Sketch of the NOKO test facility [111].

The COndenSation test rig for flow Morphology and hEAt transfer studies (COSMEA) thermal hydraulic test facility is embedded in TOPFLOW facility at Helmholtz-Zentrum Dresden-Rossendorf (HZDR), Figure 14 [46]. This facility is being used to investigate condensation of high-pressure steam inside inclined tubes corresponding to the condition of emergency condensers in passive heat removal system of the KERENA reactor. It consists of two coaxially arranged annular tubes with a stainless-steel inner (condenser) and titanium alloy outer tube (cooling side). The COSMEA facility is equipped with two novel measurement techniques. First, a set of heat flux probes installed to measure inner and outer wall temperatures in five different azimuthal positions via thermocouples resulting in calculation of the local heat flux. Second, X-ray computed tomography (CT) is applied to obtain contactless cross-sectional images of the flow morphology inside the condenser tube at five various cross sections along the tube without interfering the flow stream.

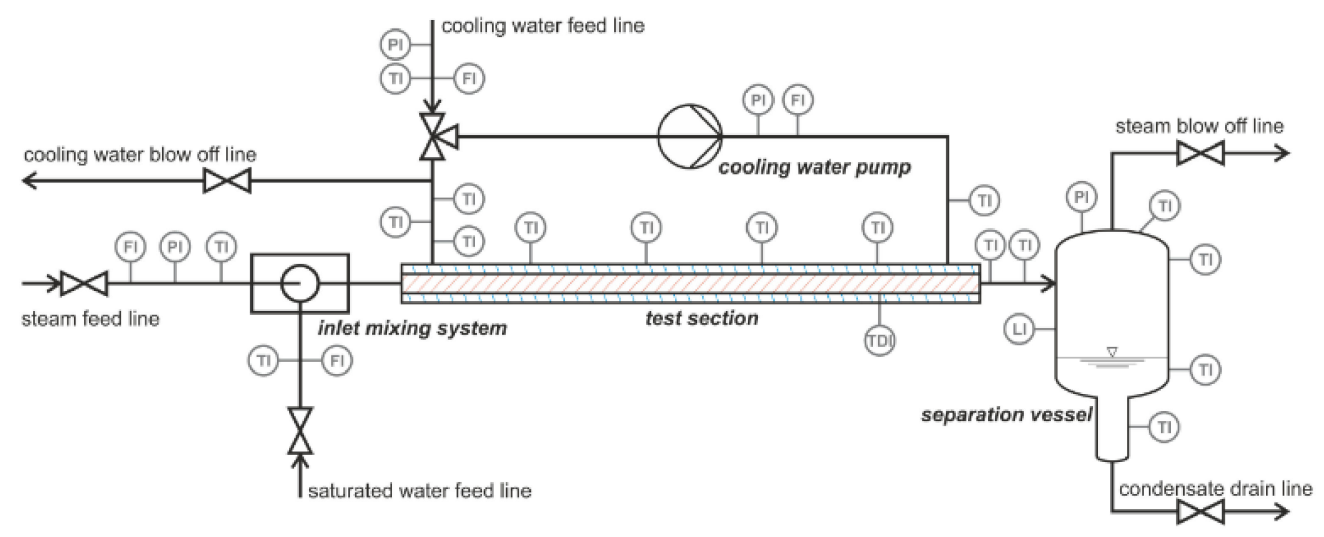

Figure 14. Sketch of the COSMEA test facility [46].

The PANDA multi-purpose facility was set up at Paul Scherrer Institute (PSI) as a scaled thermal-hydraulic test facility for investigating passive decay heat removal systems for the new generation of light water reactors (LWR) [112]. As shown in Figure 15, LWR containment volumes are 
simulated by six cylindrical pressure vessels representing the reactor, RPV, drywell, the suppression chamber (SC) and the gravity driven cooling system (GDCS) pool. The multi-purpose test facility can be applied for integral containment response tests and separate effect tests. The PANDA facility is designed for up to 10 bar pressure and $180{ }^{\circ} \mathrm{C}$ operating conditions. It's being mainly used for testing the containment features of the Economic Simplified Boiling Water Reactor (ESBWR) reactor designs in LOCA scenarios due to main steam line breaks. PANDA has been part of several research projects, among them such with investigations on the operation of building condensers of SWR 1000 (KERENA) reactor and the effect of non-condensable gases (hydrogen) on the passive containment cooling systems performance.

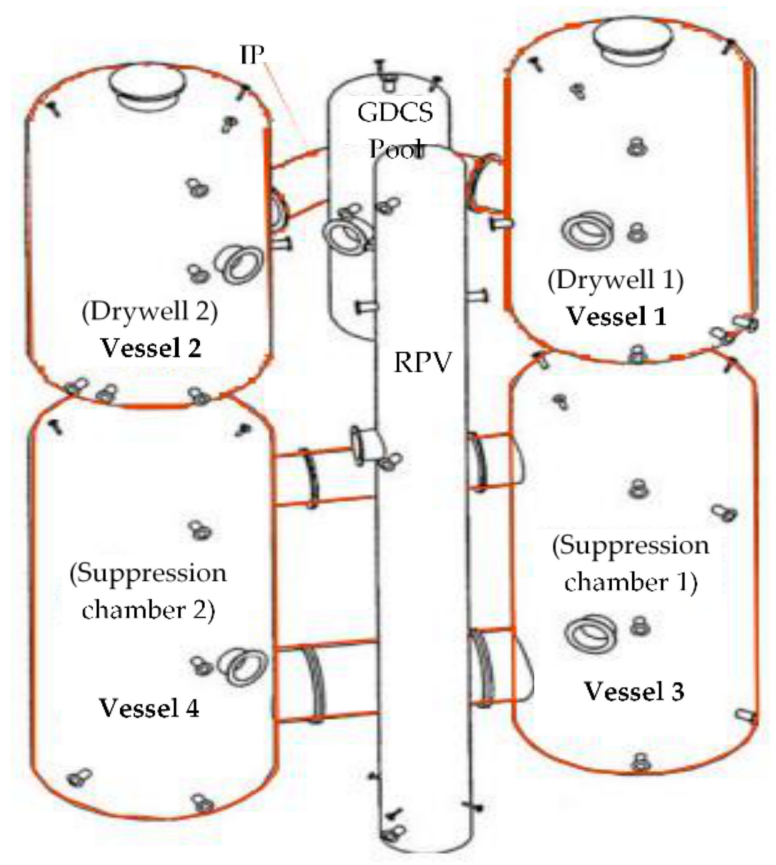

Figure 15. Sketch of the PANDA test facility [112].

The LAOKOON test facility was constructed by Goldbrunner et al. [81] at Technische Universität München to study direct contact condensation (DCC) on a subcooled water surface considering the effect of non-condensable gases at pressure levels up to 60 bar (Figure 16). Condensation in the presence of non-condensable gases occurs in the primary system of PWRs during LOCA scenarios. In the LAOKOON, nitrogen is being used as the non-condensable gas. LAOKOON equipped with a thermocouple line consisting of 12 thermocouples to measure the temperature along a vertical line as well as a laser measurement to asses concentration profiles of two-phase flow. Therefore, experiments are able to provide detailed data about temperature measurements, the water height as well as the pressure level. 


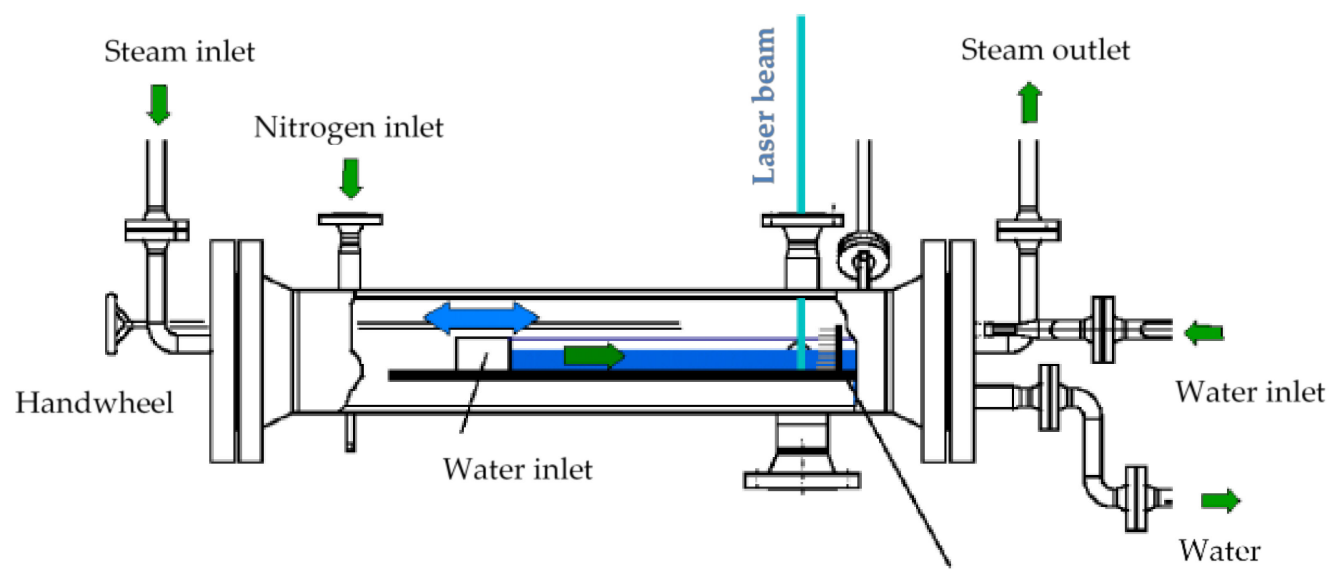

Thermocouples

Figure 16. Sketch of the LAOKOON test facility [81].

Transient condensation experiments were done by Prasser et al. [72] for the Invert Edward Pipe (INVEP). The INVEP facility contains a condensation tube ( $44.3 \mathrm{~mm}$ diameter and $5.6 \mathrm{~m}$ length) which is immersed in a tank of subcooled water (Figure 17). The test facility is equipped with novel local void probes and several micro-thermocouples along the condensation tubes. During the experiment, hot steam is produced from a pressurizer filled with a high-pressure saturated water-steam mixture. This mixture entered the nearly horizontal pipe (slight inclination approximately $1.56^{\circ}$ ) with a closed end and due to the high heat flux to the subcooled water of the tank, the phase change occurs immediately on the cold pipe of the wall.

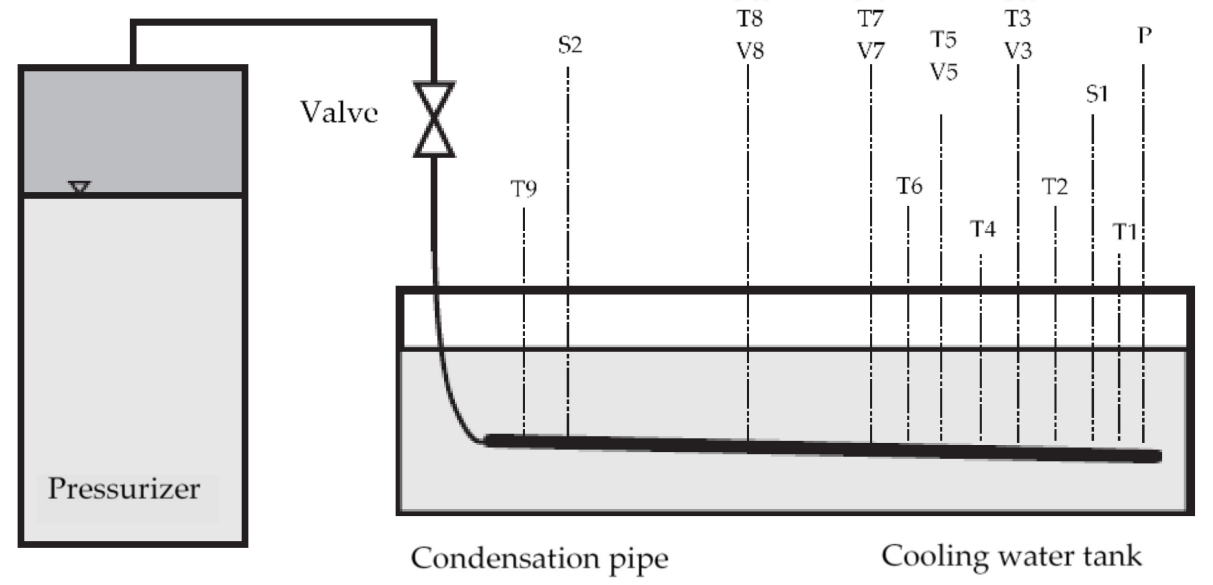

Figure 17. Sketch of the INVEP test facility; S: ordinary local void probes, T: thermocouples, V: combined thermocouple/local void probes, P: pressure measurement probes [72].

The Separate Effect Test for Condensation Modelling (SETCOM) facility at Forschungzentrum Jülich was designed with the main goal of providing data for wall condensation models development (Figure 18). This facility comprises a closed loop, which has a rectangular channel with three adiabatic walls and one cooling wall. It is capable of operating at different inclination angles from horizontal to vertical. Further to local wall heat flux measurements, it is equipped with particle image velocimetry (PIV) and a laser Döppler anemometry (LDA) instrument to provide detailed data of transport phenomena in the boundary layer $[113,114]$. 


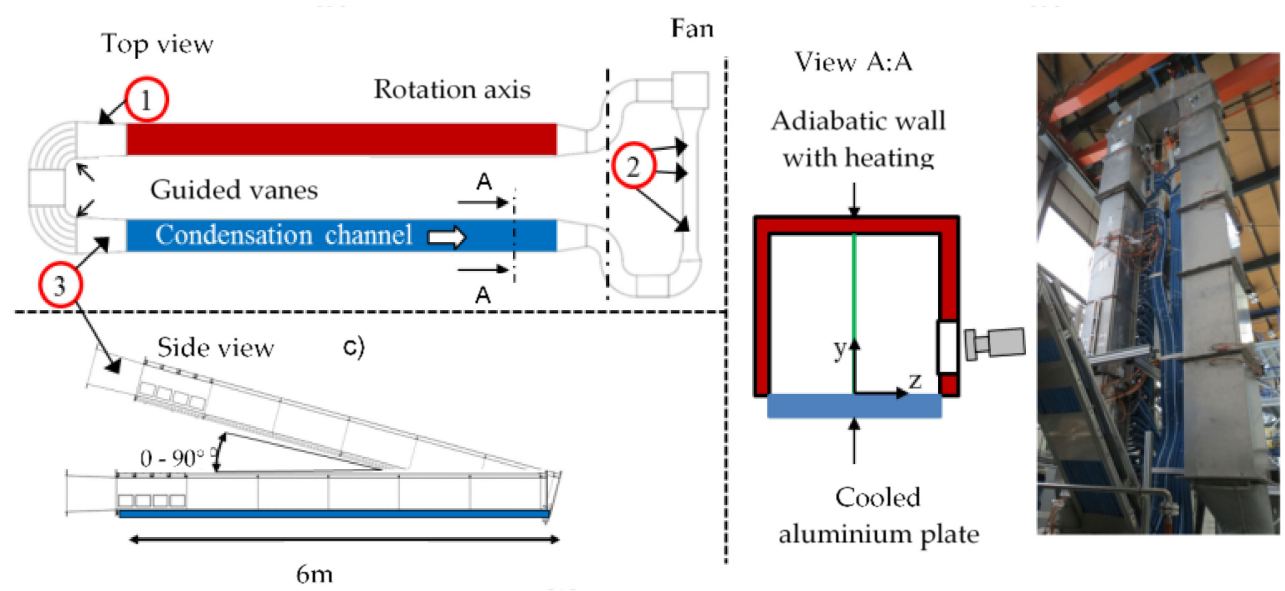

Figure 18. Sketch of SETCOM test facility [114].

The test facility GENEVA at Technische Universität Dresden was built to investigate the system and stability behavior of the CCC. Within the last years, GENEVA was enhanced to provide experimental data concerning the heat transfer behavior of the CCC. The test facility consists of three circuits: heat source circuit, test circuit, cooling circuit. In Figure 19, the test facility with the four main components is presented.

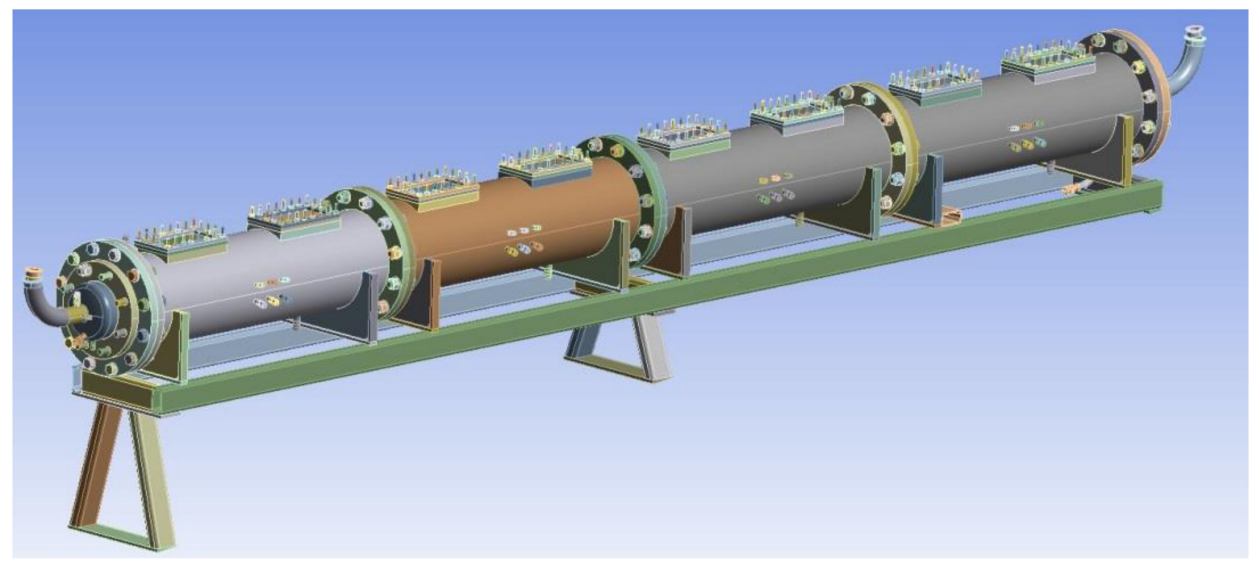

Figure 19. Schematic illustration of the test facility GENEVA [17].

Steam, which is generated by two external steam generators with a maximum electrical power of $120 \mathrm{~kW}$, is led into the steam chamber through eight nozzles (heat source circuit). Inside the steam chamber, a heat exchanger bundle of one to four tubes is arranged. This tube bundle is filled with cold deionized water and provides a circuit through the connection with the riser, heat sink and downcomer (test circuit).

Due to the colder fluid inside the tube bundle, the steam condenses at the outside. The condensation can be observed through eight windows alongside the steam chamber. The heat introduction into the fluid inside the tubes heats up and starts boiling. Since the density of water decreases with rising temperature, the fluid flows upwards the riser into the heat sink and colder fluid flows backwards via the downcomer into the tube bundle. The heat sink is connected to an external heat exchanger to provide constant conditions for the experiments [17]. The condensation process is investigated by measuring the axial and azimuthal temperature profiles on the tubes as well as the condensate mass flow and the droplet size and distribution. 


\section{Conclusions}

In this paper, the innovative passive heat removal system of BWR nuclear power plant KERENA developed by Framatome, was introduced. The essential thermal hydraulic process is based on: (1) heat removal from reactor pressure vessel to the flooding pool via four emergency condensers (EC), (2) heat removal via four containment cooling condensers (CCC) to the storage pool and shielding pool. The main phenomena can be categorized as: steam condensation inside incline tubes (EC), steam condensation on inclined tubes (CCC), boiling on inclined tubes (EC), boiling inside inclined tubes (CCC) and the natural circulation as a driving force. Part I of this review was focused on the first two categories. Commonly used models for heat transfer coefficients were introduced and assessed by comparing with COSMEA experiment data. Three different one-dimensional system codes, ATHLET, TRACE and RELAP and corresponding heat transfer correlations were introduced in detail. Furthermore, studies concerning the CFD simulations of in-tube condensation similar to the one from emergency condensers were presented. Eventually, integral and single component experimental facilities for investigation of condensation were briefly introduced. Part II of the paper is focusing on other phenomena in the passive heat removal systems such as boiling and two phase instabilities.

Author Contributions: All the authors have contributed their efforts to write the paper. A.M.S., F.V., Y.Z. and R.M. contributed in conceptualization, methodology, formal analysis, writing and original draft preparation. D.L., C.S., S.L., A.H. and U.H. supervised the work and reviewed the paper. All authors have read and agreed to the published version of the manuscript.

Funding: This research was funded by the German Federal Ministry of Education and Research (BMBF) under the contract number 02NUK041. Responsibility for the content of this publication lies with the authors.

Acknowledgments: This work is part of the research project PANAS and is funded by the German Federal Ministry of Education and Research (BMBF) under the contract number 02NUK041. Responsibility for the content of this publication lies with the authors.

Conflicts of Interest: The authors declare no conflict of interest.

\section{Abbreviations}

\section{Nomenclature}

$\begin{array}{ll}A & \text { Area }\left(\mathrm{m}^{2}\right), \text { Distribution } \\ \mathrm{C}_{\mu} & =0.09(\text { Constant }) \\ \mathrm{c}_{\mathrm{p}} & \text { Specific heat at constant pressure }(\mathrm{J} /(\mathrm{kg} \mathrm{K})) \\ \mathrm{D} & \text { Diameter }(\mathrm{m}) \\ \mathrm{D}_{\mathrm{h}} & \text { Hydraulic diameter }(\mathrm{m}) \\ \mathrm{b} & \text { Condensation coefficient } \\ \mathrm{Fr} & \text { Froude number } \\ \mathrm{f} & \text { Fanning friction factor } \\ \mathrm{f}_{\mathrm{wet}} & \text { Fraction of the surface covered by a liquid film } \\ \mathrm{G} & \text { Mass flux }\left(\mathrm{kg} /\left(\mathrm{m}^{2} \mathrm{~s}\right)\right) \\ \mathrm{Ga} & \text { Galilei number } \\ \mathrm{Gr} & \text { Grashof number } \\ \mathrm{G} & \text { Shear velocity }(\mathrm{m} / \mathrm{s}) \\ \mathrm{g} & \text { Gravitational acceleration }\left(9.81 \mathrm{~m} / \mathrm{s}^{2}\right) \\ \mathrm{H} & \text { Enthalpy }(\mathrm{J} / \mathrm{kg}) \\ \mathrm{h} & \text { Heat transfer coefficient }\left(\mathrm{W} /\left(\mathrm{m}^{2} \mathrm{~K}\right)\right) \\ \Delta \mathrm{ilv} & \text { Latent heat }(\mathrm{J} / \mathrm{kg}) \\ \mathrm{h}_{\mathrm{sf}} & \text { Superficial heat transfer coefficient }\left(\mathrm{W} /\left(\mathrm{m}^{2} \mathrm{~K}\right)\right) \\ \mathrm{Ja} & \text { Jakob number } \\ \mathrm{j}_{\mathrm{g}} & \text { Dimensionless gas velocity } \\ \mathrm{k} & \text { Turbulent kinetic energy }(\mathrm{J} / \mathrm{kg}) \\ \mathrm{K} & \text { Transfer velocity }(\mathrm{m} / \mathrm{s}) \\ & \end{array}$




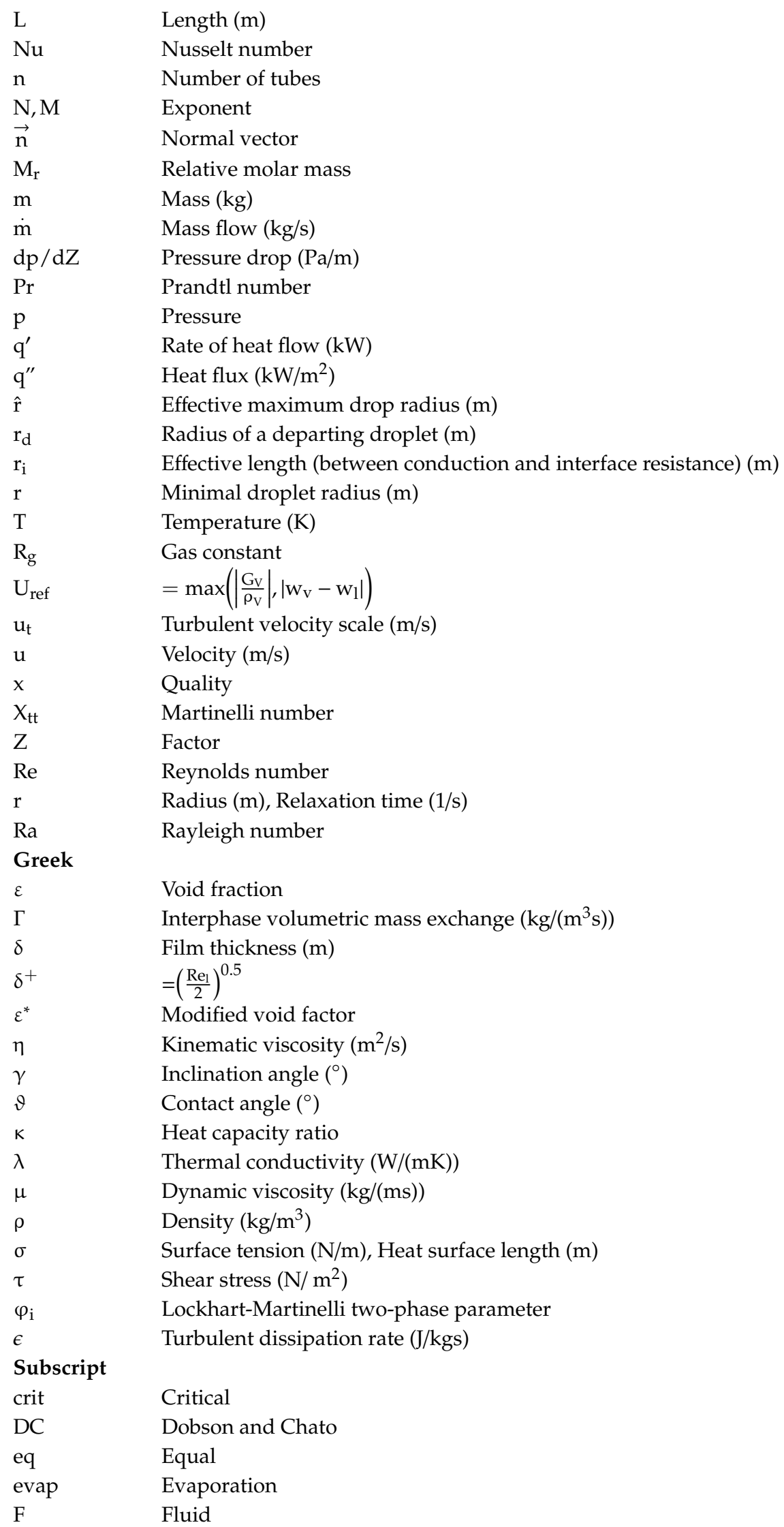




$\begin{array}{ll}\text { film } & \text { Film condensation } \\ \mathrm{g} & \text { Gas } \\ \mathrm{i} & \text { Interface } \\ \text { lam } & \text { Laminar } \\ \mathrm{l} & \text { Liquid } \\ \text { min } & \text { Minimum value } \\ \mathrm{NC} & \text { Natural convection } \\ \mathrm{o} & \text { Outside } \\ \text { strat } & \text { Stratified } \\ \mathrm{s} \text { at } & \text { Saturation condition } \\ \mathrm{TP} & \text { Two-phase } \\ \text { tot } & \text { Total } \\ \text { turb } & \text { Turbulent } \\ \text { v } & \text { Vapor } \\ \text { w } & \text { Wall } \\ \text { A } & \end{array}$

$\begin{array}{ll}\text { Abbreviations } & \\ \text { ATHLET } & \text { Analysis of thermal-hydraulics of leaks and transients } \\ \text { BWR } & \text { Boiling water reactor } \\ \text { CCC } & \text { Containment cooling condenser } \\ \text { CFD } & \text { Computational fluid dynamics } \\ \text { CMT } & \text { Core makeup tank } \\ \text { DCC } & \text { Direct contact condensation } \\ \text { DNS } & \text { Direct numerical simulation } \\ \text { DW } & \text { Drywell } \\ \text { ESBWR } & \text { Economic simplified boiling water reactor } \\ \text { EC } & \text { Emergency condenser } \\ \text { GDCS } & \text { Gravity driven cooling system } \\ \text { GRS } & \text { Gesellschaft für Anlagen- und Reaktorsicherheit } \\ \text { HZDR } & \text { Helmholtz-Zentrum Dresden-Rossendorf } \\ \text { HWR } & \text { Heavy water reactor } \\ \text { INKA } & \text { Integral Test Stand Karlstein } \\ \text { INVEP } & \text { Invert Edward pipe } \\ \text { LWR } & \text { Light water reactor } \\ \text { PCCS } & \text { Passive containment cooling system } \\ \text { PWR } & \text { Pressurized water reactor } \\ \text { PPPT } & \text { Passive pressure pulse transmitter } \\ \text { PSI } & \text { Paul Scherrer Institute } \\ \text { PTS } & \text { Pressurized thermal shock } \\ \text { RELAP } & \text { Reactor excursion and leak analysis program } \\ \text { RPV } & \text { Reactor pressure vessel } \\ \text { SC } & \text { Suppression chamber } \\ \text { SCWR } & \text { Supercritical water reactor } \\ \text { SD } & \text { Surface divergence } \\ \text { SETCOM } & \text { Separate effect test for condensation modelling } \\ \text { SRT } & \text { Surface renewal theory } \\ \text { TRACE } & \text { TRAC/RELAP advanced computational engine } \\ \text { TransAt } & \text { Transport phenomena analysis tool } \\ \text { USNRC } & \text { U.S. Nuclear Regulatory Commission } \\ \text { VOF } & \text { Volume of fluid } \\ & \end{array}$

\section{References}

1. International Nuclear Safety Advisory Group. The Safety of Nuclear Power; IAEA: Vienna, Austria, 1992.

2. Goldberg, A.; Rosner, R. Nuclear Reactors: Generation to generation; American Academy of Arts and Science: Boston, MA, USA, 2011; ISBN 978-0-9842760-0-4. 
3. Passive Safety Systems and Natural Circulation in Water Cooled Nuclear Power Plants; IAEA: Vienna, Austria, 2009; Volume 1624.

4. Passive Safety Systems in Advanced Water Cooled Reactors (AWCRs); IAEA: Vienna, Austria, 2013; Volume 1705.

5. Brettschuh, W. SWR 1000: AREVA's advanced, medium-sized boilling water reactor with passive safety features. In Proceeding of the Conference New Nuclear Power Plants Technologies 2007, Budapest, Hungary, 14-20 October 1974.

6. Heinrich, M.; Walter, M.; Oldenburg, J. Bewertung neuer Reaktorkonzepte und der Übertragbarkeit sicherheitstechnischer Lösungen auf in Betrieb befindliche Anlagen. In GRS-Gesellschaft für Anlagen- und Reaktorsicherheit mbH, GRS Abschlussberich 2012; GRS: Berlin, Germany, 2012.

7. Schaffrath, A. Experimentelle und analytische Untersuchungen zur Wirksamkeit des Notkondensators des SWR600, 100. In Jülich Forschungszentrum Zentralbibliothek 1997; JuSER: Jülich, Germany, 1997.

8. Ringel, H.; Schuster, C.; Knorr, J. Thermohydraulic behaviour of a passive pressure pulse transmitter. ATW 1995, 43, 770-775.

9. Ringel, H. Experimentelle Untersuchungen zum Verhalten und zur Beschreibung der thermohydraulischen Eigenschaften des Passiven Impulsgebers. Ph.D. Thesis, Technische Universität Dresden, Dresden, Germany, 2001.

10. Leyer, S.; Wich, S. The Integral Test Facility Karlstein-INKA. Sci. Technol. Nucl. Install. 2012, $2012,1-12$. [CrossRef]

11. Wright, R.F.; Gagnon, A.; Skinner, J.; Groome, J. Evaluation of the Scaling of the APEX-1000 Test Facility to AP1000 for Design Basis Events. In Proceedings of the 2004 International Congress on Advances in Nuclear Power Plants-ICAPP'04, Pittsburgh, PA, USA, 13-17 June 2004.

12. Huggenberger, M.; Aubert, C.; Bandurski, T.; Dreier, J.; Fischer, O.; Strassberger, H.; Yadigaroglu, H. ESBWR related passive decay heat removal tests in PANDA. ICONE-7. In Proceedings of the 7th International Conference on Nuclear Engineering, Tokyo, Japan, 19-23 April 1999.

13. Kuran, S.; Xu, Y.; Sun, X.; Cheng, L.; Yoon, H.J.; Revankar, S.T.; Ishii, M.; Wang, W. Startup transient simulation for natural circulation boiling water reactors in PUMA facility. Nucl. Eng. Des. 2006, 236, 2365-2375. [CrossRef]

14. Furuya, M. Experimental and Analytical Modeling of Natural Circulation and Forced Circulation BWRs; Delft University Press: Amsterdam, The Netherland, 2006.

15. Manera, A. Experimental and Analytical Investigations on Flashing-Induced Instabilities in Natural Circulation Two-Phase Systems. Ph.D. Thesis, Technical University of Delft, Delft, The Netherlands, 2003.

16. Schuster, C. Betriebsverhalten eines Kreislaufs mit Naturumlaufströmung. Kernenergie 1991, 34.

17. Cloppenborg, T. Passive Wärmeabfuhr. Ph.D. Thesis, TU Dresden, Dresden, Germany, 2015.

18. Juhn, P.; Kupitz, J.; Cleveland, J.; Cho, B.; Lyon, R. IAEA activities on passive safety systems and overview of international development. Nucl. Eng. Des. 2000, 201, 41-59. [CrossRef]

19. Szijarto, R. Condensation of Steam in Horizontal Pipes: Model Development and Validation. Ph.D. Thesis, ETH Zurich, Zurich, Switzerland, 2015.

20. Schaffrath, A.; Walter, D.; Delmastro, D.; Gimenez, M.; Zanocco, P. Berechnung des Notkondensators des Integralreaktors CAREM. atw International Zeitschrift für Kernenergie 2003, 48, 111-115.

21. Fukano, T. THERMOPEDIA, Thermodynamics, Heat and Mass Transfer, and Fluids Engineering. 2011. Available online: http://thermopedia.com/; (accessed on 18 December 2019).

22. Baker, O.; Petroleum, M. Desgin of pipelines for the simultaneous flow of oil and gas. In Proceedings of the Fall Meeting of the Petroleum Branch of AIME. Society of Petroleum Engineers, Dallas, TX, USA, 19-21 October 1953.

23. White, P.D.; Huntington, R.L. Horizontal co-current two-phase flow of fluids in pipe lines. Pet. Eng. 1955, 9,40 .

24. Govier, G.W.; Omer, M.M. The Horizontal Pipeline Flow of Air-Water Mixtures. Can. J. Chem. Eng. 1962, 40, 93. [CrossRef]

25. Traviss, D.P.; Baron, A.B.; Rohsenow, W.M. Forced-Convetcion Condensation inside Tubes; Mechanical Engineering Department MIT: Cambridge, MA, USA, 1971.

26. Soliman, H.M.; Azer, N.Z. Flow Patterns during condensation inside a horizontal tube. ASHRAE J. 1971, 77, 211 
27. Soliman, H.M.; Azer, N.Z. Visual studies of flow patterns during condensation inside horizontal tubes. In Proceedings of the Fifth International Heal Transfer Conference, Tokyo, Japan, 3-7 September 1974.

28. Taitel, Y.; Dukler, A.E. A model for predicting flow regime transitions in horizontal and near horizontal gas-liquid flow. Adv. Chem. Eng. 1976, 1, 47-55. [CrossRef]

29. Breber, G.; Palen, J.; Taborek, J. Prediction of horizontal tube-side condensation of pure components using flow regime criteria. Int. J. Heat Mass Transf. 1980, 102, 471-476.

30. Soliman, H. Analytical and Experimental Studies of Flow Patterns during Condensation inside Horizontal Tubes. Ph.D. Thesis, Kansas State University, Manhattan, KS, USA, 1974.

31. El Hajal, J.; Thome, J.; Cavallini, A. Condensation in horizontal tubes, part 1: Two-phase flow pattern map. Int. J. Heat Mass Transf. 2003, 46, 3349-3363. [CrossRef]

32. Kattan, N.; Thome, J.; Favrat, D. Flow boiling in horizontal tubes: Part 1-Development of adiabatic two phase flow pattern map. J. Heat Transf. 1998, 120, 140-147. [CrossRef]

33. Tandon, T.; Varma, H.; Gupta, C. A new flow regime map for condensation inside horizontal tubes. J. Heat Transf. 1982, 104, 763-768. [CrossRef]

34. Zhuang, X.; Gong, M.; Chen, G.; Zou, X.; Shen, J. Two-phase flow pattern map for R170 in a horizontal smooth tube. Int. J. Heat Mass Transf. 2016, 102, 1141-1149. [CrossRef]

35. Chato, J.C. Laminar Condensation inside Horizontal and Inclined Tubes. Ph.D. Thesis, Massachusetts Institute of Technology, Cambridge, MA, USA, 1960.

36. Nusselt, W. Die Oberflachenkondensation des Wasserdampfes. VDI-Zs 1916, 60.

37. Boyko, L.D.; Kruzhilin, G.N. Heat transfer and hydraulic resistance during condensation of steam in a horizontal tube and in a bundle of tubes. Int. J. Heat Mass Transf. 1967, 10, 361-373. [CrossRef]

38. Kosky, P.G.; Staub, F.W. Local condensing heat transfer coefficients in the annular flow regime. J. Heat Transf. 1971, 17, 1037-1043. [CrossRef]

39. Chen, S.; Gerner, F.; Tien, C. General film condensaion correlations. Exp. Heat Transf. 1987, 1, 93-107. [CrossRef]

40. Dobson, M.K.; Chato, J.C. Condensation in smooth horizontal tubes. J. Heat Transf. 1998, 120, $193-213$. [CrossRef]

41. Moser, K.W.; Webb, R.L.; Na, B. A new equivalent reynolds number model for condensation in smooth tubes. J. Heat Transf. 1998, 120, 410-417. [CrossRef]

42. Sarma, P.K.; Sastry, C.V.; Rao, C.V.; Kakac, S.; Liu, H. Convective condensation heat transfer in a horizontal condenser tube. Int. J. Therm. Sci. 2002, 41, 295-301. [CrossRef]

43. Cavallini, A.; Censi, G.; Del Col, D.; Doretti, L.; Longo, G.A.; Rossetto, L. Condensation of halogenated refrigerants inside smooth tubes. HVAC R Res. 2002, 8, 429-451. [CrossRef]

44. Cavallini, A. Condensation in horizontal smooth tubes: A new heat transfer model for heat exchanger design. Heat Transf. Eng. 2006, 27, 31-38. [CrossRef]

45. Shah, M. An improved and extended general correlation for heat transfer during condensation in plain tubes. HVAC R Res. 2009, 15, 889-913. [CrossRef]

46. Geißler, T.; Beyer, M.; Hampel, U.; Prasser, H.; Leyer, S.; Walther, M. Experimental and numerical investigation of flow structure and heat transfer during high pressure condensation in a declined pipe at COSMEA facility. In Proceedings of the 16th International Topical Meeting on Nuclear Reactor Thermal Hydraulics (NURETH-16), Chicago, IL, USA, 30 August-4 September 2015.

47. ATHLET Mod 3.1 A: User's Manual; GRS: Garching, Germany, 2016.

48. Dittus, F.; Boelter, L. Heat Transfer in Automobile Radiators of the Tubular Type; University of California Press: Berkeley, CA, USA, 1930.

49. McAdams, W. Heat Transmission; McGraw-Hill Book Company: New York, NY, USA, 1954.

50. Collier, J. Convective Boiling and Condensation; McGraw-Hill International Book: New York, NY, USA, 1981.

51. Carpenter, F.G.; Colburn, A.P. The effect of vapor velocity on condensation inside tubes. Gen. Discuss. Heat Transf. 1951, 20-26.

52. RELAP5/mod3.3 Code Manual Volume I.: Code Structure, System Models, and Solution Methods; Idaho National Engineering Laboratory: Idaho Falls, ID, USA, 2001.

53. RELAP5/mod3.3 Code Manual Volume IV.: Models and Correlations; Idaho National Engineering Laboratory: Idaho Falls, ID, USA, 2001. 
54. Sellars, J.R.; Tribus, M.; Klein, J.S. Heat transfer to laminar flows in a round tube or flat conduit. ASME 1956, 78,441 .

55. TRACE V5.0 Theory Manual; United States Nuclear Regulatory Commission: Washington, DC, USA, 2010.

56. Gnielinski, V. New equations flow regime heat and mass transfer in turbulent pipe and channel flow. Int. J. Chem. Eng. 1976, 16, 359-368.

57. Bhatti, M.S.; Shah, R.K.; Aung, W. Turbulent and Transition Flow Convective Heat Transfer in Ducts. In Handbook of Single-Phase Convective Heat Transfer; Wiley-Interscience: New York, NY, USA, 1987.

58. Incropera, F.P.; De Witt, D.P. Introduction to Heat Transfer, 2nd ed.; John Wiley \& Sons: New York, NY, USA, 1990.

59. Holman, J. Heat Transfer; McGraw-Hill Book Co.: New York, NY, USA, 1981.

60. Kuhn, S.; Schrock, V.; Peterson, P. Final Report on U. C. Berkeley, Single Tube Condensation Studies; U.C. Berekley: Berekley, CA, USA, 1994; UCB-NE-4201.

61. Schaffrath, A. Experimentelle und analytische Untersuchungen zur Wirksamkeit des Notkondensators des SWR600/1000. In Berichte des Forschungzentrums Jülich; Forschungzentrum Jülich: Jülich, Germany, 1996.

62. Schaffrath, A. KONWAR_Eine Erweiterung von ATHLET zur Berechnung der Kondensation in waagerechten Rohren. In Berichte des Forschungszentrums Jülich; Forschungszentrum Jülich: Jülich, Germany, 1997.

63. Schaffrath, A.; Krüssenberg, A.K.; Fjodorow, A.; Gocht, U.; Lischke, W. Modeling of condensation in horizontal tubes. Nucl. Eng. Des. 2001, 204, 251-265. [CrossRef]

64. Alt, S.; Lischke, W. Heat transfer in horizontal tubes during two phase natural circulation with presence of noncondensing gas. Heat Mass Transf. 2000, 36, 575-582. [CrossRef]

65. Choi, K.Y.; Park, H.S.; Kim, S.J.; No, H.C.; Bang, Y.S. Assessment and improvement of condensation models in RELAP5/MOD 3.2. Nucl. Technol. 1998, 124, 103-117. [CrossRef]

66. Choi, K.Y.; Chung, H.J.; No, H.C. Direct-contact condensation heat transfer model in RELAP5/MOP3.2 with/without noncondensable gases for horizontally stratified flow. Nucl. Eng. Des. 2002, 211, 139-151. [CrossRef]

67. Kim, H.J. Local Properties of Countercurrent Stratified Steam-Water Flow. Ph.D. Thesis, Northwestern University, Evanston, IL, USA, 1983.

68. Zhou, W.; Wolf, B.; Revankar, S. Assessment of RELAP5/MOD3.3 condensation models for the tube bundle condensation in the PCCS of ESBWR. Nucl. Eng. Des. 2013, 264, 111-118. [CrossRef]

69. Macedo, L.A.; Torres, W.M. Simulation of steam condensation in the prescence of noncondensable gases in horizontal condenser tubes using RELAP5 for advanced nuclear reactors. In Proceedings of the International Nuclear Atlantic Conference, Rio de Janeiro, Brazil, 27 September-2 October 2009.

70. Aglar, F. Assessment of the RELAP5/MOD3.3 code for condensation in the presence of air using experimental data and theoretical model. Ann. Nucl. Energy 2013, 60, 329-340. [CrossRef]

71. Szijártó, R.; Freixa, J.; Prasser, H.-M. Performance of heat transfer models of thermal-hydraulic system codes at the Invert Edwards Pipe Experiment. In Proceedings of the NOTHOS-9, Kaohsiung, Taiwan, 9-13 September 2012.

72. Prasser, H.-M.; Boettger, A.; Zschau, J.; Gocht, T. Needle shaped conductivity probes with integrated micro-thermocouple and their application in rapid condensation experiments with non-condensable gases. Kerntechnik 2003, 68, 114-120.

73. Szijártó, R.; Freixa, J.; Prasser, H.-M. Simulation of condensation in a closed, slightly inclined horizontal pipe with a modified RELAP5 code. Nucl. Eng. Des. 2014, 273, 288-297. [CrossRef]

74. Lee, K.W.; Cheong, A.; Shin, A. Assessment of condensation heat transfer models of MARS-KS and TRACE codes using PASCAL test. In Proceedings of the 25th International Conference Nuclear Energy for New Europe, Portoroz, Slovenia, 5-8 September 2016.

75. Pollman, A.; Vierow, K.; Marzo, M. Analysis of rapid-condensation transient using TRACE. Nucl. Eng. Des. 2012, 250, 512-519. [CrossRef]

76. Lee, W.H. A Pressure Iteration Scheme for Two-Phase Flow Modeling. Multiphase Transport: Fundamentals, Reactor Safety, Applications; Hemisphere Publishing: Washington, DC, USA, 1980; pp. 407-432.

77. Da Riva, E.; Del Col, D. Numerical simulation of laminar liquid film condensation in a horizontal circular minichannel. J. Heat Transf. 2012, 134, 051019. [CrossRef]

78. Qiu, G.; Cai, W.; Li, S.; Wu, Z.; Jian, Y.; Yao, Y. Numerical simulation on forced convective condensation of steam upward flow in a vertical pipe. Adv. Mech. Eng. 2014, 2014, 11. [CrossRef] 
79. Liu, Z.; Sundan, B.; Yuan, J. VOF modeling and analysis of filmwise condensation between vertical parallel plates. Heat Transf. Res. 2012, 43, 47-68. [CrossRef]

80. Szijarto, R.; Badillo, A.; Niceno, B.; Prasser, H.-M. Condensation models for the water-steamn interface and volume of fluid method. Int. J. Multiph. Flow 2017, 93, 63-70. [CrossRef]

81. Goldbrunner, M.; Karl, J.; Hein, D. Experimental investigation of heat transfer phenomena during direct contact condensation in the presence of noncondensable gas by means of linear raman spectroscopy. In Proceedings of the 10th International Symposium on Laser Techniques Applied to FluidMechanics, Lisbon, Portugal, 10-13 July 2000.

82. Nichols, B.D.; Hirt, C.W.; Hotchkiss, R.S. SOLA-VOF: A solution algorithm for transient fluid flow with multiple free boundaries. In Technical Report No. LA-8355; Los Alamos Scientific Laboratory: Los Alamos, NM, USA, 1980.

83. Hirt, C.W.; Nichols, B.D. Volume of Fluid (VOF) method for the dynamics of free boundaries. J. Comput. Phys. 1981, 39, 201-225. [CrossRef]

84. Welch, S.W.J.; Wilson, J. A volume of fluid based method for fluid flows with phase change. J. Comput. Phys. 2000, 160, 662-682. [CrossRef]

85. Zhaohui, Y.; Xiwen, Z.; Xuefang, W. Numerical simulation of condensation induced water- hammer. Tsinghua Sci. Technol. 1997, 2, 599-602.

86. Štrubelj, L.; Ézsöl, G.; Tiselj, I. Direct contact condensation induced transition from stratified to slug flow. Nucl. Eng. Des. 2010, 240, 266-274. [CrossRef]

87. Lavieville, J.; Quemerais, E.; Boucker, M.; Maas, L. NEPTUNE CFD V1.0 User Guide; EDF R\&D Chatou: Paris, France, 2005.

88. Hughes, E.D.; Duffey, R.B. Direct contact condensation and momentum transfer in turbulent separated flows. Int. J. Multiph. Flow 1991, 17, 599-619. [CrossRef]

89. Egorov, Y. Validation of CFD codes with PTS relevant test cases. In Technical report EVOL-ECORA-D07; ANSYS: Frankfurt, Germany, 2004.

90. Apanasevich, P.; Lucas, D.; Beyer, M.; Szalinski, L. CFD based approach for modeling direct contact condensation heat transfer in two-phase turbulent stratified flows. Int. J. Therm. Sci. 2015, 95, 123-135. [CrossRef]

91. Shen, L.; Triantafyllou, G.; Yue, D. Turbulent diffusion near a free surface. J. Fluid Mech. 2000, 407, $145-166$. [CrossRef]

92. Ceuca, S.C.; Macián-Juan, R. CFD Simulation of direct contact condensation with ANSYS CFX using locally defined heat transfer coefficient. In Proceedings of the ICONE-20, Anaheim, CA, USA, 30 July-3 August 2012.

93. Banerjee, S. Turbulence structure and transport mechanisms at interfaces. In Proceedings of the 9 th International Heat Transfer Conference, Boulder, CO, USA, 19-24 August 1990.

94. Hunt, J.; Graham, J. Free stream turbulence near plance boundaries. J. Fluid Mech. 1978, 84, $209-235$. [CrossRef]

95. Banerjee, S.; Lakehal, D.; Fulgosi, M. Surface divergence models for scalar exchange between turbulent streams. Int. J. Multiph. Flow 2004, 30, 963-977. [CrossRef]

96. Lakehal, D.; Fulgosi, M.; Yadigaroglu, G. Direct numerical simulation of condensing stratified flow. J. Heat Transf. 2008, 130, 021501. [CrossRef]

97. Zschaeck, G.; Frank, T.; Burns, A. CFD modeling and validation of wall condensation in the presence of non-condensable gases. Nucl. Eng. Des. 2014, 279, 137-146. [CrossRef]

98. Ambrosini, W.; Bucci, M.; Forgione, N.; Oriolo, F.; Paci, S.; Magnaud, J.; Studer, E.; Reinecke, E.; Kelm, S.; Jahn, W.; et al. Comparison and analysis of the condensation benchmark results. In Proceedings of the 3rd European Review Meeting on Severe Accident Research, Nessebar, Bulgaria, 23-25 September 2008.

99. Kuhn, S.; Peterson, P.; Schrock, V. Determination of the local heat flux in condensation experiment. Exp. Heat Transf. 1996, 9, 149-163. [CrossRef]

100. Kuhn, S.; Schrock, V.; Peterson, P. An investigation of condensation from steam-gas mixture flowing downward inside a vertical tube. Nucl. Eng. Des. 1997, 177, 53-69. [CrossRef]

101. Lehmkuhl, J.; Kelm, S.; Bucci, M.; Allelein, H. Improvement of wall condensation modeling with suction wall function for contaiment application. Nucl. Eng. Des. 2016, 299, 105-111. [CrossRef] 
102. Müller, H.; Lehmkuhl, J.; Kelm, S.; Hundhausen, A.; Belt, A.; Allelein, H.J. Development of a wall condensation model for coarse mesh containment scale applications. In Proceedings of the CFD4NRS-6, Boston, MA, USA, 13-15 September 2016.

103. Punetha, M.; Khandkar, S. A CFD based modelling approach for predicting steam condensation in the presence of non-condensable gases. Nucl. Eng. Des. 2017, 324, 280-296. [CrossRef]

104. Le Fevre, E.J.; Rose, J.W. A theory of heat transfer by dropwise condensation. In Proceedings of the 3rd International Heat Transfer Conference, Chicago, IL, USA, 7-12 August 1966.

105. Rose, J.W. Dropwise condensation theory. Int. J. Heat Mass Transf. 1981, 2, 191-194. [CrossRef]

106. Bonner, R.W. Correlation for dropwise condensation heat transfer: Water, organic fluids and inclination. Int. J. Heat Mass Transf. 2013, 61, 245-253. [CrossRef]

107. Browne, M.W.; Bansal, P.K. An overview of condensation heat transfer on horizontal tube bundles. Appl. Therm. Eng. 1999, 19, 565-594. [CrossRef]

108. The RELAP5-3D@C Code Development Team. RELAP5-3D@ Code Manual Volume IV: Models and Correlations; Idaho National Engineering Laboratory: Idaho Falls, ID, USA, 2012.

109. United States Nuclear Regulatory Commission. TRACE V5.0 Theory Manual_Field Equations, Solution Methods and Physical Models; United States Nuclear Regulatory Commission: Washington, DC, USA, 2012.

110. Prasser, H.-M.; Beyer, M.; Carl, H.; Manera, A.; Pietruske, H.; Schütz, P.; Weiß, F.P. The multipurpose thermalhydraulic test facility TOPFLOW: An overview on experimental capabilities, instrumentation and results. Kerntechnik 2006, 71, 163-173. [CrossRef]

111. Hicken, E.F.; Jaegers, H.; Jilich, F.; Schaffrath, A.; Rossendorf, F. The NOKO/TOPFLOW Facility for Natural Convection Flow; IAEA: Vienna, Austria, 2000.

112. Paladino, D.; Dreier, J. PANDA: A multipurpose integral test facility for LWR safety investigations. Sci. Technol. Nucl. Install. 2012. [CrossRef] [PubMed]

113. Allelein, H.-J.; Gupta, S.; Poss, G.; Reinecke, E.-A.; Funke, F. German Experimental Activities for Advanced Modeling and Validation Relating to Contaiment Thermal Hydraulic and Source Term; IAEA-CN-251; IAEA: Vienna, Austria, 2017.

114. Hundhausen, A.; Müller, H.; Kelm, S.; Reinecke, E.; Allelein, H. Towards CFD-Grade measurments in a condensing boundary layer-first measurments of the new SETCOM facility. In Proceedings of the 8th European Review Meeting on Severe Accident Research, Warsaw, Poland, 16-18 May 2017.

(C) 2019 by the authors. Licensee MDPI, Basel, Switzerland. This article is an open access article distributed under the terms and conditions of the Creative Commons Attribution (CC BY) license (http://creativecommons.org/licenses/by/4.0/). 